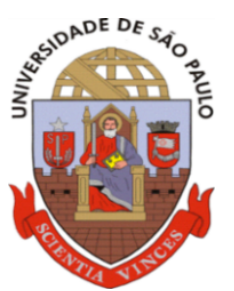

$$
\text { UNIVERSIDADE DE SÃO PAULO }
$$

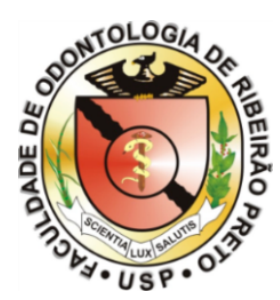

FACULDADE DE ODONTOLOGIA DE RIBEIRÃO PRETO

\author{
GLAUBER MACEDO RAMA
}

PRÓTESES PARCIAIS FIXAS APOIADAS SOBRE CONEXÃO DENTE-IMPLANTE RÍGIDA: ANÁLISE DO COMPORTAMENTO BIOMECÂNICO ANTES E APÓS CICLAGEM MECÂNICA

Versão Corrigida

Ribeirão Preto 


\section{PRÓTESES PARCIAIS FIXAS APOIADAS SOBRE CONEXÃO DENTE-IMPLANTE RÍGIDA: ANÁLISE DO COMPORTAMENTO BIOMECÂNICO ANTES E APÓS CICLAGEM MECÂNICA}

Dissertação apresentada à Faculdade de Odontologia de Ribeirão Preto da Universidade de São Paulo, para obtenção do título de Mestre no Programa de Pós-graduação em Odontologia.

Área de concentração: Reabilitação Oral

Orientador: Rossana Pereira de Almeida Antunes

Versão Corrigida

Ribeirão Preto 


\section{AUTORIZO A REPRODUÇÃO E DIVULGAÇÃO DO TEOR TOTAL OU PARCIAL DESTE TRABALHO, POR QUALQUER MEIO CONVENCIONAL OU ELETRÔNICO, PARA FINS DE ESTUDO E PESQUISA, DESDE QUE CITADA A FONTE.}

\section{FICHA CATALOGRÁFICA}

Elaborada pela Biblioteca Central do Campus USP - Ribeirão Preto

Versão corrigida da Dissertação. A versão original se encontra

disponível na unidade que aloja o programa

Rama, Glauber Macedo

Próteses parciais fixas apoiadas sobre conexão dente-implante rígida: Análise do comportamento biomecânico antes e após ciclagem mecânica.

Ribeirão Preto, 2014.

68p. : il.; $30 \mathrm{~cm}$

Dissertação de Mestrado apresentada à Faculdade de Odontologia de Ribeirão Preto/USP. Área de concentração: Reabilitação Oral.

Orientador: Antunes, Rossana Pereira de Almeida

1. Conexão dente-implante. 2. Prótese sobre implante. 3. Ciclagem mecânica. 4. Fotoelasticidade. 


\section{FOLHA DE APROVAÇÃO}

Glauber Macedo Rama

Dissertação apresentada à Faculdade de Odontologia de Ribeirão Preto da Universidade de São Paulo, para obtenção do título de Mestre no Programa de Pós-graduação em Odontologia.

Área de concentração: Reabilitação Oral

Aprovado em:

\section{Banca Examinadora}

1) Prof.(a). Dr.(a).:

Instituição:

Julgamento:

Assinatura:

2) Prof.(a). Dr.(a).:

Instituição:

Julgamento: Assinatura:

3) Prof.(a). Dr.(a).:

Instituição:

Julgamento: Assinatura: 
DEDICATÚRIA 
Às vezes frente às adversidades tropeçamos, cedemos, mas temos inúmeras pessoas que nos ajudam, nos apoiam e nos auxiliam em nossa caminhada. Nestes dois anos e meio de árduo trabalho, isto não foi diferente.

Assim, dedico este trabalho:

À DEUS, por me ofertar a vida, a saúde e as inúmeras oportunidades sem as quais não seria possivel que eu chegasse onde cheguei junto de pessoas tão queridas e amadas;

Aos meus pais, Gilmar e Maria José, por todos os sacrificios que fizeram desde minha infância para oferecer a mim e à minha irmã as melhores oportunidades possivivis para nossa caminhada pessoal, profissional e ética. Estiveram presentes na exaltação dos momentos de alegria e comemoração e sempre ao meu lado nos momentos de dúvida elou fraqueza. Presença imprescindivel em minha vida;

À minha irmã Elkiane e meu cunhado-irmão Rodrigo, que mesmo distantes, nunca mediram esforços em me apoiar nesta caminhada e me ajudar naquilo que era possivel dentro das limitações da distância;

À minha querida noiva, Ana Laura, parceira, amiga, paciente, colaboradora, cúmplice e extremamente incentivadora. Só Deus sabe o quanto você me motivou e colaborou em todos os momentos de alegrias e dificuldades, sempre com uma palavra de conforto e parcimônia para seguir em frente. Amo você!

Ao meu grande amigo-irmão Danilo Maeda Reino, amigo para todas as horas e uma excelente companhia para inúmeras discussões profissionais de extremo crescimento. Se cheguei onde cheguei, você é um dos grandes responsáveis!

Ao meu mestre de referência, Prof. Dr. Wilson Matsumoto, grande incentivador do meu ingresso à carreira acadêmica. Devo muito do que sei e executo ao senhor, que se tornou muito mais do que um mestre, mas sim um grande amigo para a vida toda. 
AgRAdEcimentas 


\section{Agradecimentas Especiais}

A Profa. Dra. Rossana Pereira de Almeida Antunes, minha orientadora e grande amiga, que me acolheu na pós-grduação e enfrentou junto comigo todos os obstáculos desta jornada. Frente a uma dificuldade, sempre tivemos excelentes discussões sobre como proceder e qual caminho tomar, contribuindo enormemente para meu crescimento profissional acadêmico. Pessoa admirável, de caráter sem igual que levo como referência para minha vida toda como um exemplo de grande docente e pesquisadora.

À Ana Paula Macedo, técnica de laboratório, cujo auxílio e sugestões puderam contribuir de forma grandiosa para o desenvolvimento dessa pesquisa. Sua contribuição seja na metodologia, seja no tratamento estatístico dos dados e até mesmo nas horas de discussão sobre a interpretação destes foram de fundamental importância para a execução deste trabalho. Essa conquista não é apenas minha, mas sim nossa!

Aos amigos Danilo Maeda Reino e Prof. Dr. Wilson Matsumoto, aos quais também dedico esta obra, só tenho a agradecer pelo incentivo e pelo apoio durante toda a execução deste trabalho. Ter vocês como referência profissional foi o que me deu forças, junto às sugestões técnicas, para a conclusão de minha pesquisa com êxito. 


\section{Agradecimentos}

Um trabalho como este não é feito por um, dois ou cinco pesquisadores. É feito por uma equipe representada por inúmeras pessoas que direta ou indiretamente puderam propiciar sua execução. Sendo assim, palavras faltariam para agradecer a todos que me auxiliaram nesta jornada. Venho a agradecer:

À Faculdade de Odontologia de Ribeirão Preto da Universidade de São Paulo, que pôde me acolher não apenas nos meus 4 anos de graduação, mas também nestes 2 anos e meio de pós-graduação. Levo a entidade como uma segunda casa de suma importância para minha vida, tendo um carinho enorme e um orgulho muito grande de ter feito parte de sua história;

Ao curso de Pós-graduação em Odontologia (Reabilitação Oral), em nome da Profa. Dra. Fernanda de Carvalho Panzeri Pires de Souza, coordenadora do curso, pela dedicação para com a entidade e o curso, sempre a disposição para nos defender e auxiliar durante nosso período ingresso. Venho também agradecer de forma especial por todo o auxílio à minha pesquisa, cedendo uma das máquinas de ciclagem mecânica do Laboratório Integrado de Pesquisa em Biocompatibilidade de Materiais (LIPEM) para que eu pudesse executar meu trabalho à tempo;

Aos Profs. Drs. Renata Cristina Silveira Rodrigues Ferracioli, Maria da Glória Chiarelo de Mattos e Ricardo Faria Ribeiro por ter compartilhado momentos tão bons no laboratório e nas aulas, nunca medindo esforços para me auxiliar e viabilizar a execução de meu trabalho;

Aos demais professores que contribuíram para minha formação durante os anos de mestrado através de disciplinas ministradas ou conversas de corredor, em especial a Alma Blasida Concepcion Elizaur Benitez Catirse, Andréa Candido dos Reis, Cláudia Helena Lovato da Silva, Helena de Freitas Oliveira Paranhos, Iara Augusta Orsi, Luiz Carlos Pardini, Raphael Freitas de Souza, Ricardo Henrique Alves da Silva, Regina Maura Fernandes, Takami Hirono Hotta, Valéria Oliveira Pagnano de Souza e Valdir Antônio Muglia. 
Aos colegas de pós-graduação ingressantes no mesmo periodo :Denise Pupim, Danilo Zaparolli, Eduardo Andrés Borie Echevarría, Franciele Mendes, Gustavo da Col dos Santos Pinto, Karen Pintado Palomino, Luciana Costa Crizóstomo, Maurício Malheiros Badaró, Martha Gonzalez, Esquerra, Nathalia Ramos, Talita Dantas, Suleima do Vale dentre outros colegas mestrandos e doutorandos, pelos momentos de coleguismo e amizade;

Em especial, aos meus grandes amigos Danilo Flamini Oliveira e Raniel Fernandes Peixoto. Se estou onde estou e cheguei onde cheguei, isso é graças em grande parte a vocês. Obrigado realmente por todos os momentos de discussão cientifica e de palavras amigas, podem realmente contar comigo para o que precisarem;

A todos os funcionários da Faculdade de Odontologia de Ribeirão Preto (FORPUSP): Adriana Cláudia Lapria Faria Queirós, Regiane de Cássia Tirado Damasceno, Fernanda Talita de Freitas, Isabel Cristina Galino Sola, Mary Possani Carmessano, Regiane Cristina Moi Sacilotto, Ana Paula Xavier, Paulo Sérgio Ferreira, Marcelo Aparecido Vieira, Fernando Schiavetto, Odair Rosa Silva, José de Godoi Filho e Luis Sérgio Soares que de uma maneira ou de outra foram tão importantes na minha formação. Em especial, venho agradecer ao Ricardo de Souza Antunes e Edson Volta pela dedicação e paciência durante meus procedimentos de ciclagem mecânica;

Aos Técnicos em Prótese Dentária João Carlos da Silva (DentLab) e Lício Firmino Júnior (Protécnica), cujo auxílio e participação foram ferramentas fundamentais para a execução técnica deste trabalho, em especial na confecção de diversas etapas dos corpos de prova;

À Coordenação de Aperfeiçoamento de Pessoal de Nível Superior (CAPES), pela bolsa de estudos a mim concedida durante os anos de curso de Mestrado.

Á FAPESP pelo financiamento deste estudo. Processo 2011/11190-0. 
Esta pesquisa foi desenvolvida no Laboratório de Estudos Biomecânicos em Prótese e Implantes do Departamento de Materiais Dentários e Prótese da Faculdade de Odontologia de Ribeirão Preto da Universidade de São Paulo. 
RESUMロ 


\section{RESUMO}

RAMA G.M.. Próteses parciais fixas sobre conexão dente-implante rígida: Análise do comportamento biomecânico antes e após ciclagem mecânica. 2014. 69p. Dissertação (Mestrado em Reabilitação Oral) - Faculdade de Odontologia de Ribeirão Preto, Universidade de São Paulo, Ribeirão Preto, 2014.

A associação entre dente e implante em uma prótese parcial fixa (PPF) vêm sido questionada há muitos anos devido a suas implicações clínicas, incluindo a seleção do melhor tipo de união dos elementos protéticos (conexão rígida ou semi-rígida). Este estudo avaliou próteses dento-implanto-suportadas de conexão rígida do tipo cimentada sobre 3 tipos de conexão protética (hexágono externo - HE, hexágono interno - HI e cone morse - $\mathrm{CM}$ ) e sua relação com o desajuste vertical e falhas na prótese antes e após ciclagem mecânica, além da análise fotoelástica destas situações. Foram confeccionados 21 corpos de prova ( $7 \mathrm{HE}, 7 \mathrm{HI}$ e $7 \mathrm{CM}$ ) sobre um modelo mestre que simulou a perda dentária dos elementos 46 e 47, sendo um implante posicionado na área do 47 e um dente preparado com ligamento periodontal simulado em poliéter na área do 45. Sobre este modelo foram confeccionadas PPFs metalocerâmicas de 3 elementos rígidas cimentadas sobre dente e implante (munhão universal). Os corpos de prova foram preparados e submetidos ao ensaio de ciclagem mecânica com uma carga de $120 \mathrm{~N}$ por 1.000 .000 de ciclos, simulando o uso clínico da prótese por 2 anos. Análises do desajuste vertical foram realizadas por meio de microscopia óptica (40x) em todos os períodos de confecção das PPFs (antes da solda, após solda, após aplicação da cerâmica e após ciclagem). O percentual de falhas nas próteses após ciclagem também foi avaliado (trincas/fraturas/decimentações), além da execução do ensaio fotoelástico (carga pontual dental, bipontual nos pilares e oclusal simultânea).

Os resultados obtidos para o desajuste vertical indicaram um aumento significante dos níveis de desajuste para todas as etapas de confecção tanto para dente quanto implante $(p<0,0001)$, porém não significante entre os grupos $(p>0,059)$. Para o percentual de falhas na prótese, encontrou-se um índice decrescente na ordem $\mathrm{CM}>\mathrm{HI}>\mathrm{HE}$. Para análise fotoelástica, encontrou-se um índice de concentração de tensões crescente na ordem $\mathrm{CM}<\mathrm{HI}<\mathrm{HE}$.

Baseado nos resultados encontrados, dentro das limitações do estudo foi possível concluir que: os níveis de desajuste vertical tendem a aumentar nas etapas de confecção da prótese para todas as conexões protéticas; a fadiga mecânica tende a interferir no grau de desajuste vertical a longo prazo pela deformação da estrutura a depender de sua espessura; o aumento no percentual de falhas da prótese tende a ser proporcional ao aumento da rigidez da conexão protética; apesar da redução da rigidez da conexão protética favorecer a longevidade da PPF, esta também tende a aumentar as tensões nos elementos pilares e stress no osso circundante; a utilização da conexão Morse subcrestal para união dente-implante rígida tende a ser preferível pela preservação dos elementos pilares devido a menor concentração de tensões em detrimento da longevidade da PPF, entretanto esta pode ser substituída caso a falha seja irreversível.

Palavras-chave: Conexão dente-implante, prótese sobre implante, ciclagem mecânica, fotoelasticidade. 
Abstract 


\begin{abstract}
RAMA G.M.. Tooth-implant supported rigid connected fixed partial dentures: Biomechanical behavior analysis before and after mechanical cycling. 2014. 69p. Dissertação (Mestrado em Reabilitação Oral) - Faculdade de Odontologia de Ribeirão Preto, Universidade de São Paulo, Ribeirão Preto, 2014.
\end{abstract}

The association between tooth and implant in fixed partial dentures (FPD's) have been questioned for many years due to its clinical implications, including selecting the best kind of connection design (rigid or semi-rigid connection). This study assessed cemented toothimplant supported rigid connected FPD's on 3 types of implant connections (external hexagon - EH, internal hexagon - IH and morse taper - MT) and its relationship to the vertical misfit and FPD failure before and after mechanical cycling plus the photoelastic analysis of those situations. 21 specimens ( $7 \mathrm{EH}, 7 \mathrm{IH}$ and $7 \mathrm{MT}$ ) were fabricated on a master model that simulated tooth loss of elements 46 and 47, with an implant placed on the 47 area and a prepared tooth with simulated periodontal ligament in polyether on the 45 area. On this model, three-element metalloceramic rigid FPD's were made, cemented to tooth and implant (universal post). The specimens were prepared and subjected to mechanical cycling with a $120 \mathrm{~N}$ load under 1,000,000 cycles, simulating a 2-year clinical use of the prosthesis. Analyses of vertical misfit were performed by optical microscopy (40x) in all periods of FPD's fabrication (before welding, after welding, after application of ceramic and after cycling). The FPD failure percentage after cycling was also evaluated (cracks/fractures/loss of cementation), and photoelastic test was performed (dental load only, simultaneous abutment load and occlusal load).

The results for vertical misfit indicated a significant increase in the levels of misfit for all stages of fabrication for both tooth and implant $(p<0.0001)$ but not significant between groups $(p>0.059)$. For the FPD failure percentage, we found a decreasing rate in the order $\mathrm{MT}>\mathrm{IH}>\mathrm{EH}$. The photoelastic test indicated a major amount of tension increase in the order $\mathrm{MT}<\mathrm{IH}<\mathrm{EH}$.

Based on these results, within the limitations of the study it was concluded that: the levels of vertical misfit tend to increase in the prosthesis fabrication steps for all implant connections; mechanical fatigue tends to interfere on vertical misfit in long term due to deformation of the framework depending on its thickness; the FPD failure percentage tends to be proportional to the rigidity increase of the implant connection; despite the decrease of rigidity of the implant connection favors the longevity of the FPD, this also tends to increase tensions on the abutments and stress on the surrounding bone; the use of subcrestal morse taper connection on rigid tooth-implant FPD's tends to be preferable for the preservation of the abutments due to the lower abutment stress concentration at the expense of longevity of FPD, though this can be replaced if the failure is irreversible.

Keywords: tooth-implant connection, implant supported prosthesis, mechanical cycling, photoelastic analysis 
SUMÁRIO 


\section{SUMÁRIO}

1. INTRODUÇÃO _ 18

2. PROPOSIÇÃO__ 26

3. MATERIAL E MÉTODO _ 28

3.1 OBTENÇ̃̃O DO MODELO MESTRE: _____________________ 29

3.2 PADRONIZAÇÃO DO LIGAMENTO PERIODONTAL ___ 31

3.3. OBTENÇÃO DA ESTRUTURA METÁLICA DAS PRÓTESES PARCIAIS FIXAS RÍGIDAS- PPFS _—_ 31

3.4. OBTENÇÃO DA COBERTURA EM CERÂMICA PRENSADA____ 34

3.5 ENSAIO DE CARGA MECÂNICA CÍCLICA___________ 36

3.6 DESAJUSTE VERTICAL: OBTENÇÃO E ANÁLISE DOS DADOS ____ 41

3.7 PERCENTUAL DE FALHAS NA PRÓTESE: OBTENÇÃo E ANÁLISE DOS DADOS____ 43

3.8 ENSAIO FOTOELÁSTICO: OBTENÇÃO DAS IMAGENS E ANÁLISE QUALITATIVA ____ 44

4. RESULTADOS 47

4.1 DESAJUSTE VERTICAL: ________________ 48

4.2 PERCENTUAL DE FALHAS NA PRÓTESE (ANÁLISE DESCRITIVA): ___________ 51

4.3 ANÁLISE FotoElÁSTICA (ANÁLISE DESCRITIVA): ___________ 51

5. DISCUSSÃO — 55

6. CONCLUSÕES _ _ 61

7. REFERÊNCIAS BIBLIOGRÁFICAS _ 63 


\section{INTRロDUÇÃ̃}


No início da implantodontia, a experiência com restaurações implantossuportadas em pacientes com edentulismo parcial sempre foi menos favorável do que para os pacientes totalmente edêntulos. Entretanto, o entendimento mais aprofundado e os novos desenvolvimentos técnicos têm elevado o sucesso dessas reabilitações. Para melhorar a estabilidade e minimizar as complicações é importante considerar a estabilidade mecânica das próteses fixas implantossuportadas (Bragger et al., 2005).

As próteses parciais fixas implantossuportadas são uma eficiente alternativa de tratamento para pacientes com pequenas perdas dentais. Entretanto, limitações anatômicas, falhas de osseointegração ou dentes periodontalmente comprometidos que requerem ferulização podem criar uma situação em que seja necessária a conexão entre implante e dente natural por meio de uma prótese parcial fixa.

Algumas razões podem levar a indicação da união dente-implante; a mais comum são as limitações nas áreas posteriores onde há tecido ósseo insuficiente para a colocação de implantes, o que leva a indicação de uma prótese mista apoiada sobre dente natural e implante. A perda de implantes com limitações cirúrgicas ou financeiras para nova inserção e a necessidade de esplintagem de dentes naturais comprometidos periodontalmente são outras razões para a indicação de próteses apoiadas sobre dentes e implantes (Chee et al., 2010; Hoffmann, Zafiropoulos, 2010; Mamalis et al., 2010).

Lindh (2008) questiona se dentes deveriam ser extraídos, o que pode ser definido como "eutanásia dental”, para se evitar a combinação dente-implantes. De acordo com o autor, após extensa revisão sistemática sobre o assunto, não há suporte científico para uma afirmativa de que seria melhor extrair dentes do que fazer a associação, não havendo razão para que se indique a extração de um dente só para se evitar a conexão dente-implante. Há inúmeros estudos controlados que comparam esse tipo particular de próteses com as implantossuportadas onde as complicações e índices de longevidade são similares. 
Com relação ao tipo de conexão da prótese fixa há muitas escolas de pensamento. Há uma linha de pensamento que advoga o uso de mecanismo de conexão não rígida devido a diferença na mobilidade do dente natural e do implante. Outros preferem a conexão rígida devido menor frequência de falhas mecânicas, havendo, ainda quem diga que a conexão dente-implante não deveria ser realizada.

De acordo com Chee et al. (2010) do ponto de vista teórico a conexão não rígida com o attachment próximo ao dente parece ser vantajoso, pois biomecanicamente isso permitiria um movimento fisiológico do dente sob forças oclusais. Mas algumas experiências clínicas correlacionam esse tipo de conexão com a intrusão de dentes naturais, (Block et al., 2002) o que pode reduzir o suporte do abutment aumentando a carga no implante e suporte ósseo, e permitindo a migração de dentes oponentes (Nishimura et al., 1999).

Devido a essas complicações, o tipo de conexão rígida tem promovido maior sucesso, embora diminua os efeitos da tensão no osso, pode aumentar as tensões nos implantes e na prótese, principalmente se houver algum comprometimento periodontal (Carrillo et al., 2010). Para Lindh et al. (2001) a conexão rígida pode prevenir a intrusão dental consideravelmente.

Com relação a essa conexão dente natural-implante há divergências de opinião, principalmente devido a diferença na mobilidade do dente quando comparada ao implante osseointegrado. O dente natural saudável periodontalmente apresenta mobilidade de 50$200 \mu \mathrm{m}$ enquanto a mobilidade do implante osseointegrado fica em torno de $10 \mu \mathrm{m}$. Além disso, os limites de percepção tátil também são diferentes nas duas condições, sendo maior para os dentes naturais. (Mamalis et al., 2010).

A diferença de mobilidade entre dente natural e implante está na proporção de 5:1, o que provoca torque significante no implante (Weinberg; Kruger, 1994). O sistema de implante usado exerce influência e deveria permitir algum grau de flexibilidade dentro da união parafusada, por exemplo, no sistema de hexágono externo a junção tem movimento 
comparável ao dente natural (Gunne et al., 1997; Lundgreen; Laurell 2000). O tipo de conexão com hexágono interno aumenta a estabilidade da prótese, mas ao mesmo tempo pode aumentar a concentração de tensões, indicando que a utilização de implantes de hexágono externo seria mais favorável (Silva et al., 2010). Poucos trabalhos, entretanto, relataram o uso da conexão morse para este tipo de união.

A intrusão é o grande problema quando dentes e implantes são unidos por uma prótese, ocorrendo em níveis que variam de 3,5 a 44\% (Block et al., 2002). A intrusão do dente natural promove desconforto ao paciente e é um problema de difícil resolução. Outros problemas como perda da osseointegração, maior perda óssea, falhas na fixação e falhas técnicas envolvendo afrouxamento de parafusos e perda ou fratura de abutments também são relatadas (Naert et al., 2001; Bragger et al., 2005). Fraturas de implantes, causando complicações restauradoras, cirúrgicas e psicológicas, também foram relatadas (VelásquezPlata et al., 2002).

Gunne et al. (1999) promoveram um estudo longitudinal comparativo in vivo em 23 pacientes com ausências dentárias de dentes mandibulares posteriores. De um dos lados foi proposta a confecção de uma prótese implantossuportada sobre 2 implantes e do outro lado uma prótese parcial fixa unindo dente (elemento pilar anterior) e implante (elemento pilar posterior), avaliando-se a taxa de sucesso dos implantes, presença de falhas mecânicas e perda óssea cervical após um período de 10 anos. As conclusões obtidas foram de que a união dente-implante não mostrou-se prejudicial às taxas de sucesso em 10 anos e seu uso pode ser considerado a depender da situação clínica encontrada.

Naert et al. (2001) promoveram dois estudos, sendo um clínico e um radiográfico, no qual analisaram as possíveis complicações da união dente-implante a longo prazo. Dois grupos de 123 pacientes cada tiveram próteses parciais fixas confeccionadas, sendo 339 implantes ligados a 313 dentes (grupo teste) e 329 implantes ligados entre si (grupo controle) 
por próteses parciais fixas rígidas. Os pacientes foram acompanhados por períodos de tempo de até 15 anos após instalação das próteses. As taxas de sucesso acumuladas (ausência de mobilidade de implantes, fraturas ou decimentações) foram de $95 \%$ para o grupo teste e 98,5\% para o grupo controle, porém após análise estatística esta diferença não se mostrou significante. Entretanto, houve um maior índice de tendência à fraturas dentais, intrusão dental, decimentações e infiltração por cáries e mobilidade dental para o grupo teste, logo os autores julgam a união dente-implante como sendo uma alternativa secundária à reabilitação, dando-se preferência à reabilitação implantossuportada apenas.

Em outro estudo multicêntrico de Lindh et al. (2001), o grupo teve por objetivo investigar a taxa de sobrevivência de implantes e a perda óssea ao redor de implantes e dentes quando estes eram unidos em próteses parciais fixas por meio de conexões rígidas e semirígidas. Após um levantamento em clínicas na Suécia, 185 implantes em 111 pacientes foram avaliados seguindo um protocolo que levava em consideração a indicação do tratamento, radiografias iniciais e de acompanhamento além de informações quanto a complicações. As taxas acumuladas de sucesso encontradas foram de 95,4\% para um acompanhamento de 3 anos e o principal achado clínico preocupante além da perda de implantes (6 de 185) e periimplantite (4 de 183) foi a intrusão dental, presente em $5 \%$ dos casos e geralmente relacionada a conexões semi-rígidas. Os autores concluem que a união pode ser considerada um tratamento previsível e que, quando preconizada, deve-se preferir a união rígida para se evitar a possibilidade de intrusão do elemento dental.

Trabalhando com uma revisão sistemática seguida de meta-análise, Lang et al. (2004) avaliaram a taxa de sucesso/sobrevivência da associação entre dentes e implantes em próteses parciais fixas em um período de 5 a 10 anos, seja por meio de conexões rígidas ou semirígidas entre eles. Para inclusão na revisão sistemática, os critérios levados em consideração consistiam em estudos de coorte prospectivos ou retrospectivos com seguimento de pelo 
menos 5 anos em média. Nestes estudos, era necessário que o paciente fosse avaliado clinicamente em cada visita de retorno e os trabalhos foram selecionados por 2 revisores separadamente. Dos cerca de 3844 trabalhos pesquisados, apenas 13 foram selecionados para meta-análise por se enquadrarem nos critérios de inclusão. Após análise dos dados, obteve-se um índice médio de sobrevivência dos implantes de $90,1 \%$ e $82,1 \%$ para 5 e 10 anos de acompanhamento, respectivamente. Para as próteses, o índice de sobrevivência foi de 94,1\% e $77,8 \%$ respectivamente para 5 e 10 anos. Após 5 anos de acompanhamento, observou-se intrusão do elemento dental em cerca de $5,2 \%$ dos casos, quase sempre realizados com conexões semi-rígidas. Tendo em vista que resultados da literatura têm mostrado taxas de sucesso superiores quando a associação dente-implante é evitada, os autores acreditam que deve-se analisar com cautela cada caso e que, quando for realizado, prefira-se a conexão rígida.

Em outra revisão de casos clínicos realizados acerca das complicações biológicas e técnicas inerentes à união dente-implante em prótese parcial fixa, Nickenig et al. (2006) acompanharam casos de 84 próteses em 83 pacientes (sendo 132 pilares dentes e 142 implantes) com uma média de 4,73 anos de acompanhamento. Após esse período, notou-se que $10 \%$ das próteses necessitaram de alguma intervenção técnica devido a danos (fraturas na cerâmica, fraturas na estrutura, troca total da prótese). Notou-se também que as intervenções/correções técnicas foram bem menos frequentes em próteses com conexão dente-implante rígida. Os autores concluíram que as complicações dependem da conformação mecânica da prótese utilizada e que resultados muito semelhantes a próteses implantossuportadas podem ser atingidos quando a conexão dente-implante for feita de forma rígida para o período de acompanhamento avaliado.

Os estudos de fotoelasticidade foram introduzidos na odontologia por Noona et al. (1949) e demonstram a qualidade, quantidade e distribuição das forças por padrões de franjas 
que aparecem como uma série sucessiva e contínua de bandas de cores diferentes, onde cada uma delas representa um grau diferente de birrefringência correspondendo a magnitude das tensões naquela região. É uma técnica que tem sido extensivamente utilizada como uma ferramenta descritiva para avaliar a característica da força transmitida (Cehreli et al., 2004), podendo no caso ser utilizada para estudo do comportamento deste tipo de união protética em uma situação in vitro.

Em contraste com os trabalhos apresentados anteriormente, Ozçelik et al. (2007) em um estudo in vitro investigaram estruturas de próteses parciais fixas unindo dente-implante com conexões rígidas e semi-rígidas pelos métodos de análise fotoelástica e de elementos finitos em 2D. Três situações foram simuladas (conexão rígida, semi-rígida na área do dente e semi-rígida na área do implante) e observou-se os mais altos níveis de tensão no osso periimplantar para a conexão rígida e índices menores para as semi-rígidas, tendo-se um resultado superior quando o conector semi-rígido se localiza próximo ao implante. Os autores concluem que mecanicamente uma conexão semi-rígida mostra-se superior para a união dente-implante devendo ser preconizada.

Ainda considerando trabalhos in vitro que utilizaram a análise fotoelástica como método de avaliação, Da Silva et al. (2010) avaliaram a conexão dente-implante com diferentes desenhos (rígida ou semi-rígida) em diferentes conexões protéticas (hexágono externo e hexágono interno). Após análise descritiva das imagens obtidas, observou-se uma menor concentração de tensões para as conexões rígidas e semi-rígidas para o implante hexágono externo do que para o implante hexágono interno, no qual a conexão semi-rígida mostrou-se a mais desfavorável. A justificativa encontrada pelo grupo se daria pela maior maleabilidade da conexão hexágono externo, que dissiparia as tensões na conexão minimizando-as nos tecidos periimplantares, ao contrário do implante hexágono interno que por ser uma conexão mais rígida poderia implicar numa maior transmissão de tensões. 
Assim, pode-se observar que essa é uma área de estudos muito controversa, com limitados estudos para a avaliação do prognóstico de próteses fixas suportadas por dentes e implantes (Mamalis et al., 2010), havendo necessidade de mais estudos longitudinais (Carrillo et al., 2010). Embora a união dente natural-implante seja um assunto controverso, ainda, e em muitas situações clínicas sua indicação é o único modo de se realizar a reabilitação de um paciente. O risco-benefício deve ser apresentado ao paciente e as complicações devem ser apresentadas para que haja um consenso antes de se finalizar o plano de tratamento. 
2. PRAPRSIÇÃ̃ 
Este estudo teve como objetivos a análise do comportamento biomecânico de próteses fixas rígidas associando-se dentes naturais e implantes de diferentes conexões protéticas em área posterior da mandíbula, focando-se em:

- Análise do desajuste vertical antes da soldagem, após solda, após aplicação da cerâmica e após ciclagem mecânica;

- Análise do percentual de falhas da prótese (trincas, fraturas, decimentações) após a ciclagem mecânica;

- Análise fotoelástica qualitativa - para observação da distribuição de cargas no dente natural, implante e osso circundante. 
3. Material e Métudo 
O modelo analisado representa a perda de um primeiro molar inferior (46) e do segundo molar inferior (47), com perda óssea na região do 46, presença do pré-molar inferior natural (45) com implante na região do segundo molar inferior (47).

\subsection{Obtenção do modelo mestre:}

Iniciou-se o processo de confecção do modelo mestre pela obtenção do elemento dental 45 preparado. Para tal, um dente de estoque foi desgastado por meio de uma ponta diamantada em alta-rotação (3228, KG Sorensen, Cotia, SP, Brasil) utilizando os princípios de desgaste para uma coroa total metalocerâmica. Para padronização da quantidade de desgaste e da inclinação, o dente foi fixado perpendicularmente a uma matriz cilíndrica de PVC preenchida por gesso por meio de um delineador modificado e depois preparado em um dispositivo desenvolvido na oficina de Precisão do Departamento de Materiais Dentários e Prótese (FORP-USP), que fixa uma caneta de alta rotação ao aparelho tornando o processo de desgaste o mais padronizado possível. O dente preparado foi desincluído do gesso e duplicado 21 vezes em resina bis-acrílica (Protemp 4, 3M ESPE, Seefeld, Alemanha) para posterior utilização nos corpos de prova a serem ciclados(figura 1).
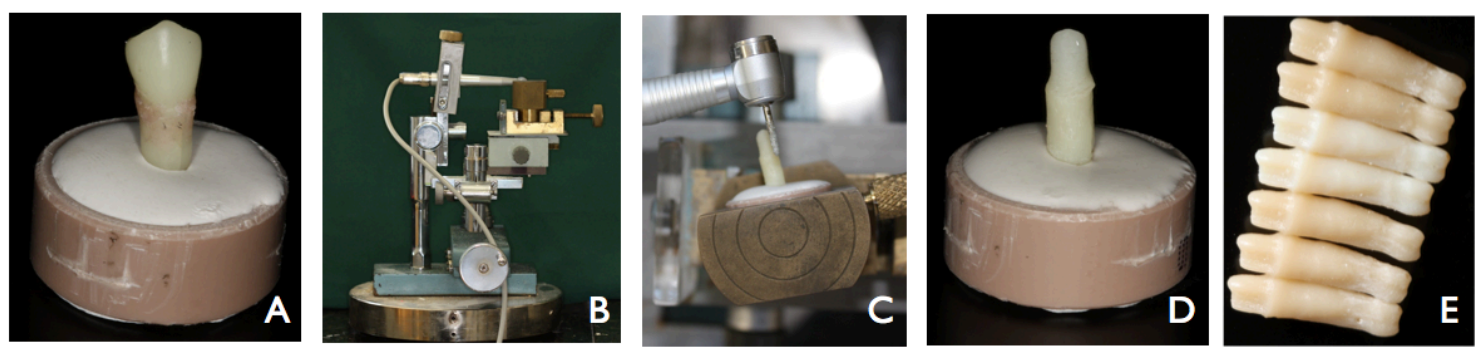

Figura 1. Confecção de preparo no elemento dental. A - Inclusão em gesso; B e C - Dispositivo para preparo padronizado; D - Elemento dental preparado; E - Elementos dentais replicados em bis-acril. 
Um bloco de policarbonato incolor recebeu duas perfurações paralelas na região dos dentes 45 e 47. Por meio de um delineador modificado, o dente foi inserido em sua respectiva perfuração e fixado com cola adesiva de contato (Super-Bonder, HenckelLoctite Adesivos LTDA, Itapevi, SP, Brasil) por 24 horas.

Três tipos de conexões protéticas foram testadas no trabalho por meio de implantes (Neodent, Curitiba, PR, Brasil) com as respectivas medidas: conexão tipo hexágono externo (HE) 3,75X13,0mm, conexão tipo hexágono interno (HI) 3,75x13,0mm e conexão tipo conemorse (CM) 3,75x13,0mm. Para cada situação dos diferentes tipos de implantes foram confeccionadas sete próteses parciais fixas rígidas cimentadas $(n=7)$. Sendo assim, na área do implante (dente 47) no modelo mestre, um pilar para prótese cimentada do tipo Munhão Universal Cone-Morse 4,5x4,0x2,5 (Neodent, Curitiba, PR, Brasil) foi parafusado a um análogo e fixado no modelo $1,5 \mathrm{~mm}$ abaixo da superfície, simulando a filosofia de trabalho empregada pelo fabricante. Desta forma, o término do munhão se deu $1 \mathrm{~mm}$ acima da superfície e pôde ser equivalente aos munhões universais dos implantes HE e HI (implantes instalados ao nível ósseo) uma vez que sua menor cinta metálica é de $1 \mathrm{~mm}$ de altura(figura 2).

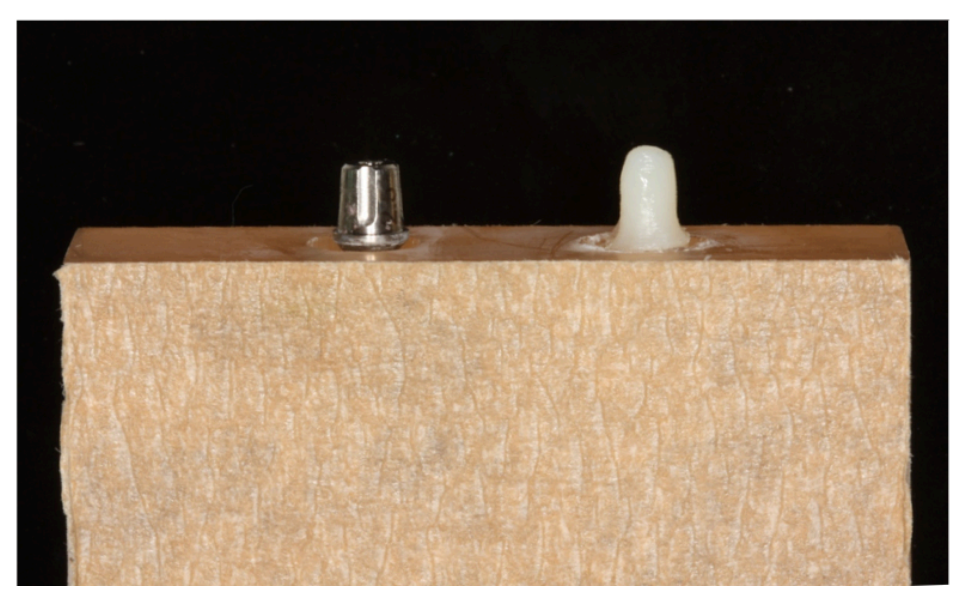

Figura 2. Modelo mestre em policarbonato contendo elemento dental e implante (proteção do modelo com fita crepe para evitar riscos em sua superfície nos processos de confecção das peças). 


\subsection{Padronização do ligamento periodontal}

Para a simulação do ligamento periodontal as réplicas do dente 45 receberam uma cobertura de poliéter (ImpregumSoft ${ }^{\circledR}, 3 \mathrm{MESPE}$, Seefeld, Alemanha). A raízes dos dentes artificiais foram imersas em banho de cera para escultura numa espessura aproximada de $300 \mu \mathrm{m}$ (Hohmann et al., 2007) e foram moldadas com silicone de condensação; após a polimerização do material o dente artificial foi removido criando-se um molde para obtenção padronizada do ligamento periodontal pelo sistema de mufla/contra-mufla em silicone (figura $3)$.
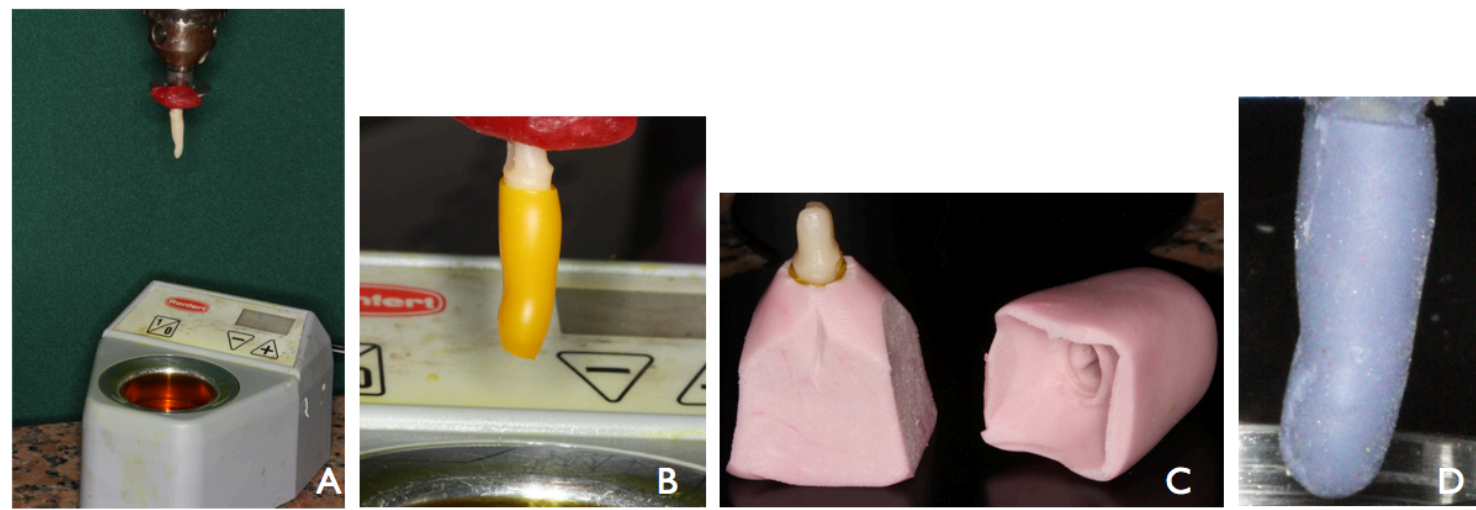

Figura 3. - Padronização ligamento periodontal. A e B - Banho de cera por imersão; C - Matriz em silicone para duplicação; D - Ligamento periodontal em poliéter finalizado.

\subsection{Obtenção da estrutura metálica das próteses parciais fixas rígidas-PPFs}

Com o modelo mestre em mãos, iniciou-se o enceramento anatômico (GEO Natural, Renfert GmbH,Hilzigen, Alemanha) de uma PPF de três elementos após a inserção de um cilindro calcinável para Munhão Universal sobre o pilar. Após sua finalização, confeccionouse uma camada de gengiva artificial (Gingifast - Zhermack, Badia Polesine, Itália) na região ao redor dos pilares e abaixo do pôntico e sobre o conjunto uma matriz bipartida em silicone de adição pesada/leve (Virtual - Ivoclar Vivadent, Liechtenstein, Alemanha) para duplicação do enceramento(figura 4). 

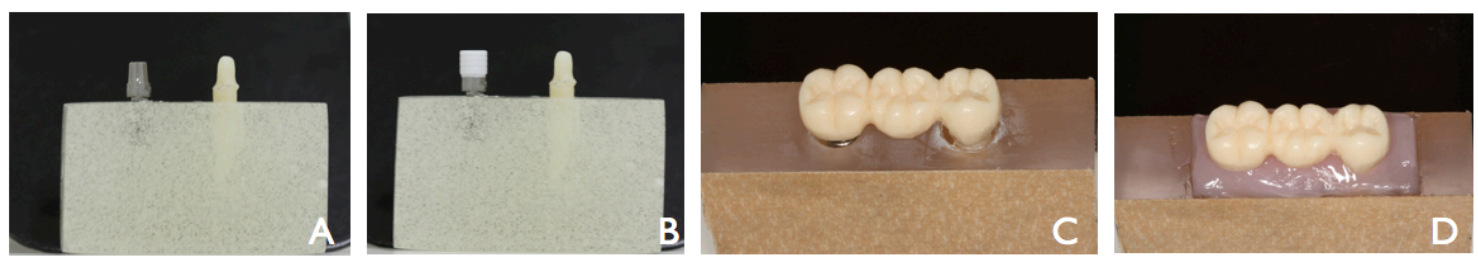

Figura 4. Enceramento anatômico da PPF. A - Modelo mestre; B - Colocação do cilindro calcinável sobre o munhão; C - Enceramento finalizado; D - Camada de gengiva artificial aplicada sob o enceramento.

Uma quantidade de cera para escultura em esferas (Schuler-Dental, Johanesstrabe, Alemanha) liquefeita foi vertida na matriz por meio de um conta-gotas aquecido e este enceramento duplicado foi reduzido em 1,5 a $2 \mathrm{~mm}$ para liberação do espaço referente ao revestimento cerâmico estético posterior. A calibração da redução da cera foi feita periodicamente por meio da matriz em silicona bipartida inicial. Ao obter-se o enceramento reduzido, uma nova matriz bipartida em silicona pesada e leve (Virtual - Ivoclar Vivadent, Liechtenstein, Alemanha) foi confeccionada e 20 novos enceramentos reduzidos foram duplicados para fundição das estruturas metálicas totalizando 21 enceramentos ( 7 para cada tipo de conexão protética). Estes foram armazenados um recipiente contendo água e álcool para manutenção da estabilidade dimensional até à inclusão nos anéis de silicone (figura 5).
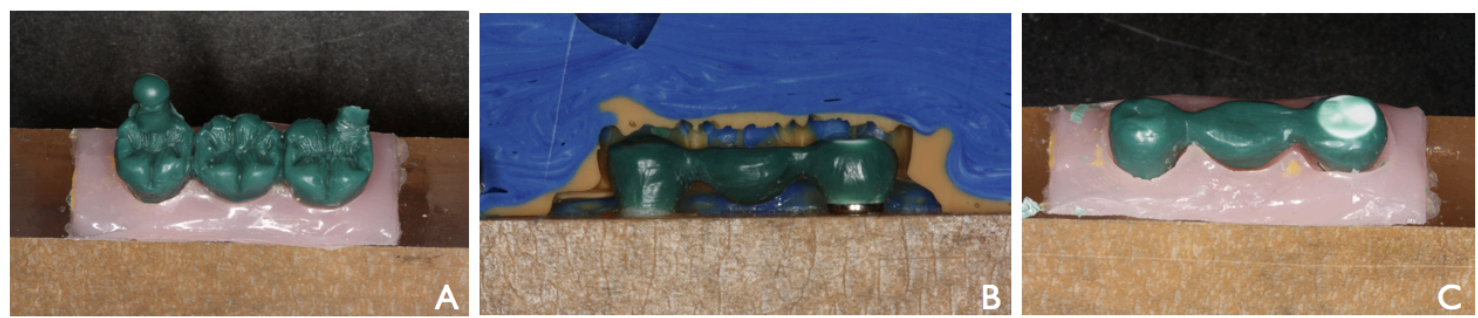

Figura 5. Redução do enceramento para determinação da estrutura metálica. A - Duplicação do enceramento anatômico inicial; B - Checagem do espaço para o revestimento estético com a matriz em silicona; C Enceramento com redução finalizado.

As estruturas enceradas receberam sprues para fundição e foram fixadas em 7 anéis de silicone, sendo 3 estruturas por anel. Um spray anti-bolhas foi utilizado para minimizar o risco de formação das mesmas e o revestimento fosfatado (HeatShock, Polidental SA, Brasil), espatulado à vácuo, foi vertido sob vibração constante nos 7 anéis. Após 24 horas, os anéis preparados foram submetidos a ciclo térmico em forno elétrico (EDG10P-S, EDG, São 
Carlos, SP, Brasil)para permitir a expansão do revestimento e eliminação da cera, onde foram aquecidos até uma temperatura de $950^{\circ} \mathrm{C}$ e fundidos em liga de Níquel-cromo-titânio (Ni-CrTi, Tilite Press, Talladium INC, USA). As fundições foram realizadas na máquina Discovery Plasma (EDG, São Carlos, SP, Brasil), que promove fusão por arco voltaico de corrente contínua através de eletrodo de tungstênio, sobre crisol (cadinho) especial de cobre, sob vácuo e atmosfera inerte de argônio(figura 6).
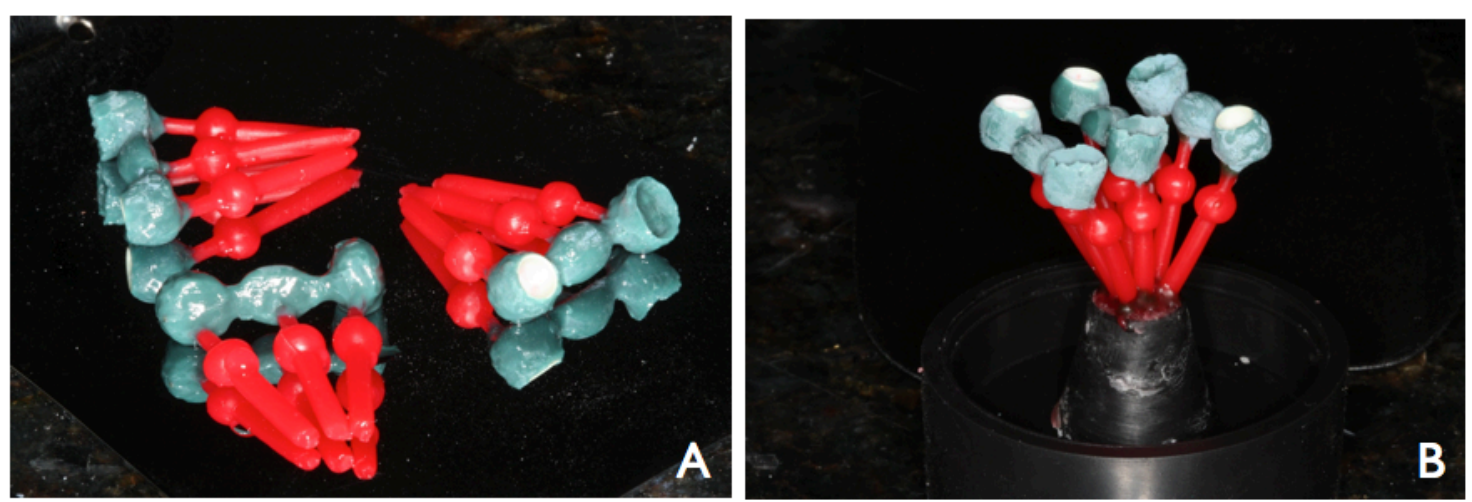

Figura 6. Estruturas preparadas para fundição. A - Sprues posicionados; B - Estruturas posicionadas nos anéis de silicone (3 por anel).

Após o processo de fundição e adequado resfriamento do revestimento em temperatura ambiente, as estruturas foram desincluídas por meio de uma prensa hidráulica (EDG, São Carlos, SP, Brasil) e em seguida o revestimento foi removido com um martelo pneumático. Os condutos de alimentação foram seccionados com discos de carborundum e pequenos nódulos e irregularidades foram removidos com brocas de tungstênio em alta rotação sob refrigeração constante. As próteses foram jateadas com óxido de alumínio (Polidental SA, Brasil) de granulação de $100 \mu \mathrm{m}$, com auxílio da máquina Mult Jet III (EDG, São Carlos, Brasil) sob pressão de $80 \mathrm{lib} / \mathrm{pol}^{2}$ ou 90 Psi $\left(5,62 \mathrm{kgf} / \mathrm{cm}^{2}\right)$, até a total remoção do revestimento, externa e internamente.

Para melhor passividade no assentamento das peças, optou-se pela secção das estruturas em monobloco por meio de uma máquina cortadora de precisão com disco diamantado na área do conector distal e posterior soldagem. Utilizou-se uma máquina de 
solda TIG/arco de plasma de argônio (DENTA PUK, Lampert, Werneck, Alemanha) para a união dos retentores. O procedimento de soldagem foi realizado sobre o modelo mestre, estando ambos os retentores com efetiva passividade em relação a seus respectivos pilares antes da união. Na região cervical do pôntico também foi soldada uma pequena haste metálica proveniente da fundição de um fio de cera de $1 \mathrm{~mm}$ de espessura com objetivo de estabilizar a peça no processo de prensagem cerâmica posterior.

\subsection{Obtenção da cobertura em cerâmica prensada}

As estruturas soldadas e bem acabadas foram jateadas no trijato (Basic Classic, Renfert, Hilzingen, Alemanha) com partículas de óxido de alumínio de $150 \mu \mathrm{m}$ (Asfer, São Caetano do Sul, SP, Brasil), sob pressão de 40 lib/pol ${ }^{2}$ e imersas em recipiente com álcool isopropílico e levados à cuba ultrassônica (Ultrasonic Cleaner, Odontobrás, Ribeirão Preto, SP, Brasil), onde permaneceram em agitação por 10 minutos. Nos segundos finais do processo de agitação, com a cuba ainda em funcionamento, as estruturas foram removidas, evitando a deposição por decantação de resíduos sobre as peças. As peças foram secas com jatos de ar isento de umidade e óleo. Em seguida, as estruturas foram levadas ao forno de cerâmica (Alumini Sinter Press, EDG, São Carlos, SP, Brasil) sobre um refratário para que a queima do óxido fosse realizada (degaseificação). Sob vácuo relativo, as estruturas foram colocadas a uma temperatura de $550^{\circ} \mathrm{C}$, e esta aumentada $55^{\circ} \mathrm{C}$ por minuto, até que atingisse $970^{\circ} \mathrm{C}$. Com a temperatura alcançada, o vácuo foi liberado e aguardou-se o resfriamento das estruturas para então ser realizada a aplicação da primeira camada de opaco (IPS In Line PoM Opaquer, A2, Ivoclar Vivadent, Liechtenstein, Alemanha). O opaco foi aplicado sobre as estruturas metálicas com auxílio de um pincel em toda sua extensão em uma fina camada, em seguida as estruturas foram levadas ao forno de cerâmica para a queima, seguindo todas as recomendações do fabricante. Após a queima da primeira camada de opaco, esperou-se 
novamente o resfriamento e aplicou-se uma segunda camada, sendo a queima realizada imediatamente após sua aplicação, originando a espessura de opacificador de aproximadamente $0,1 \mathrm{~mm}$.

Estando as camadas de opaco aplicadas, realizou-se o enceramento no formato final da prótese fixa. Para tal, utilizou-se a matriz bipartida em silicona de adição (Express XT, 3M ESPE, Seefeld, Alemanha) confeccionada previamente para a redução do enceramento durante as fases de confecção da estrutura metálica. O enceramento foi realizado simulando a anatomia dental, fornecendo espessura de cera de aproximadamente $1,5 \mathrm{~mm}$ sobre toda a extensão da infraestrutura metálica.

A matriz em silicone foi posicionada sobre modelo mestre, estando a infraestrutura metálica assentada e cera plastificada foi gotejada com auxílio de um gotejador de vidro aquecido em lamparina. Para a plastificação da cera foi utilizado plastificador com regulagem digital da temperatura de fusão (Hotty LED, Renfert GmbH, Hilzigen, Alemanha). Após o resfriamento da cera, a matriz foi removida, obtendo-se o enceramento da prótese fixa. Para cada estrutura, foi necessário que se fizesse um refinamento desse enceramento, principalmente na região cervical, uma vez que a cera liquefeita não preenchia com perfeição todos os espaços da matriz. O enceramento das coroas foi realizado com cera orgânica (GEO Natural, Renfert GmbH, Hilzigen, Alemanha), própria para enceramentos de peças a serem trabalhadas com cerâmica prensada, uma vez que, para se trabalhar com esta técnica faz-se necessário que a cera seja eliminada completamente, não restando nenhum resíduo, para que não haja contaminação da cerâmica e, consequentemente, seu manchamento por pigmentos provenientes da não eliminação total da cera (figura 7). 

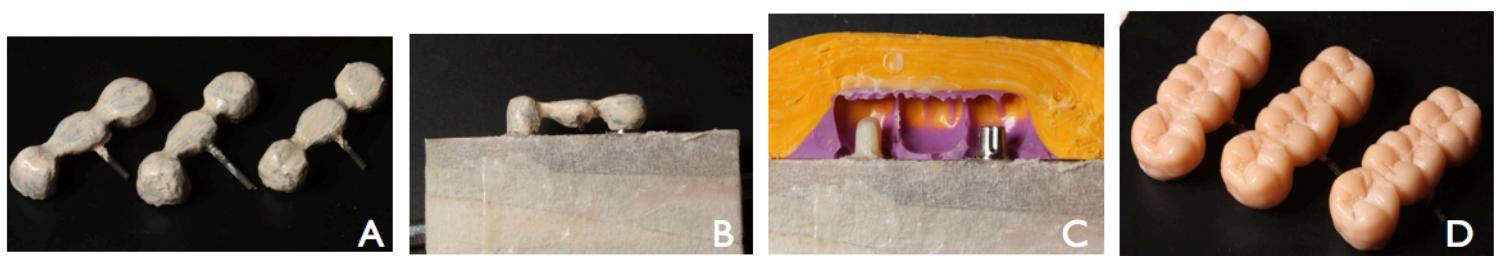

Figura 7. Duplicação do enceramento sobre o opaco para aplicação do revestimento estético cerâmico. A Estruturas com opaco aplicado; B - Estrutura assentada sobre o modelo mestre; C - Colocação de matriz em silicone para padronização do volume de cera e anatomia; D - Enceramentos finalizados prontos para injeção cerâmica.

As peças enceradas foram enviadas ao laboratório de prótese Protécnica - Ribeirão Preto para injeção e prensagem cerâmica (IPS In Line POM, IvoclarVivadent, Liechtenstein, Alemanha), segundo as recomendações do fabricante. As peças receberam, após a desinclusão, jateamento, acabamento e polimento para posterior utilização nos ensaios mecânicos (figura 8).

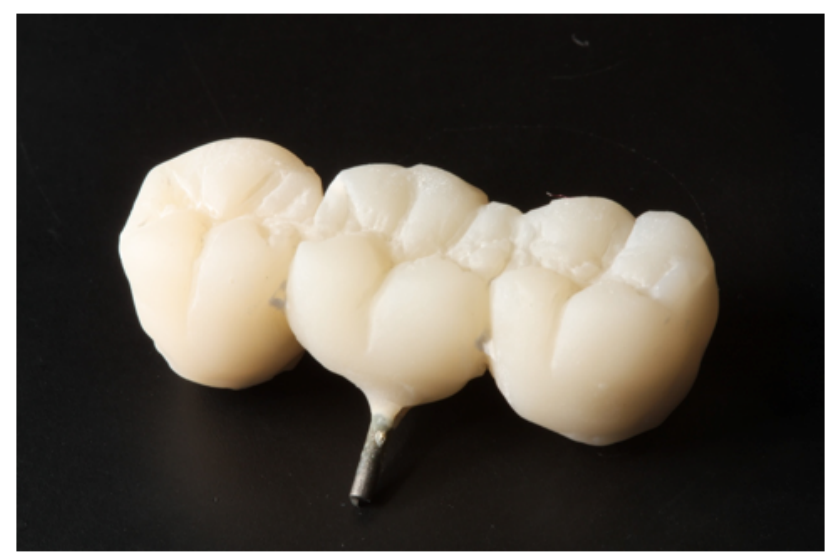

Figura 8. PPF finalizada após aplicação do revestimento estético cerâmico.

\subsection{Ensaio de Carga Mecânica Cíclica}

Para a ciclagem mecânica, 21 corpos de prova em poliuretano foram confeccionados. A técnica utilizada consistiu na colocação de um transferente do munhão universal sobre o pilar no modelo mestre e moldagem do conjunto com silicona de adição (Virtual, Ivoclar Vivadent, Liechtenstein, Alemanha) pesada/leve. Esta mesma matriz de silicona foi fixada em sua parte superior a um delineador por meio de um parafuso, de forma que todo o conjunto permanecesse perpendicular ao solo. Após a presa do material este foi sacado do modelo 
mestre e reservado para posterior utilização (figura 9).
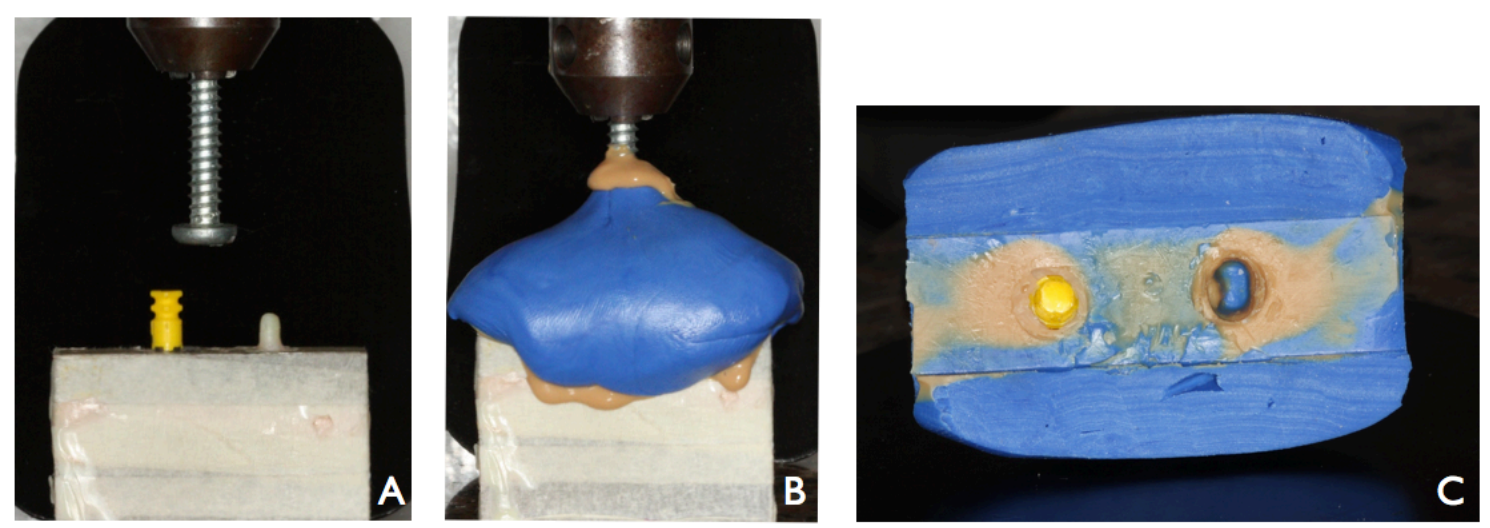

Figura 9. Confecção dos corpos de prova em poliuretano para ciclagem. A - Adaptação do transferente sobre o munhão; B - Moldagem de transferência com silicona unida ao parafuso do delineador; C - Molde de transferência.

Cada um dos implantes (7 HE, 7 HI e 7 CM) recebeu seu respectivo munhão universal 4,5 x 4,0 com o torque recomendado pelo fabricante. Para tal, cada implante foi protegido por uma tira de lixa e fixado a uma pequena morsa, tendo seu respectivo componente torqueado por uma catraca protética (32N para HE, $20 \mathrm{~N}$ para $\mathrm{HI}$ e $32 \mathrm{~N}$ para $\mathrm{CM})$. Após 10 minutos do torque inicial, este foi novamente verificado com a catraca manual(figura 10).
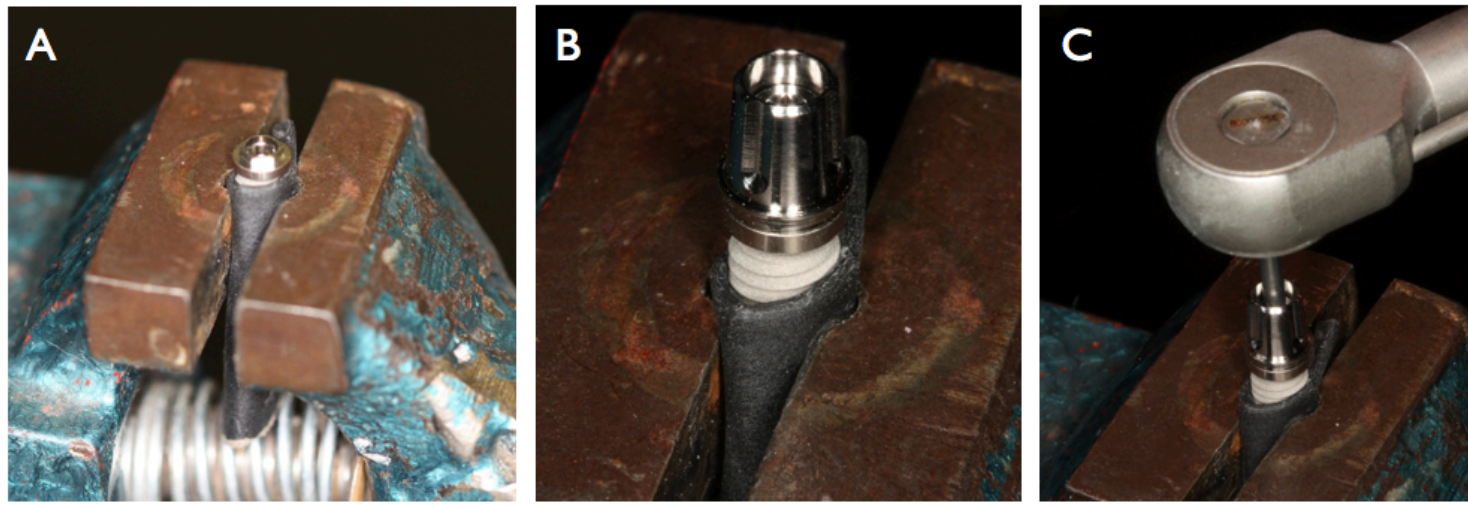

Figura 10. Torque dos munhões nos respectivos implantes. A - Fixação do implante em morsa; B Parafusamento do munhão sobre o implante; C - Torque do componente por meio da catraca torquímetro seguindo as recomendações do fabricante.

Para acomodação do poliuretano foram fabricadas matrizes cilíndricas metálicas de 25 $\mathrm{mm}$ de diâmetro e $20 \mathrm{~mm}$ de altura. O molde em silicona foi novamente fixado ao delineador 
e tanto um implante com seu respectivo pilar já torqueado quanto um dente já com ligamento periodontal em poliéter preparado foram encaixados no molde. O poliuretano foi então preparado (F16, Axson Technologies, Saint-Ouen-1'Aumône, França) e vertido na matriz metálica. Em seguida, o conjunto molde-implante-dente foi deslocado verticalmente para baixo através das hastes do delineador até que os términos do pilar e do dente estivessem a nível $1 \mathrm{~mm}$ superior ao poliuretano, de forma que o poliuretano se mantivesse ao nível da plataforma para os implantes HE e HI e sobre a plataforma cerca de 1,5 mm para os implantes CM (figura 11).
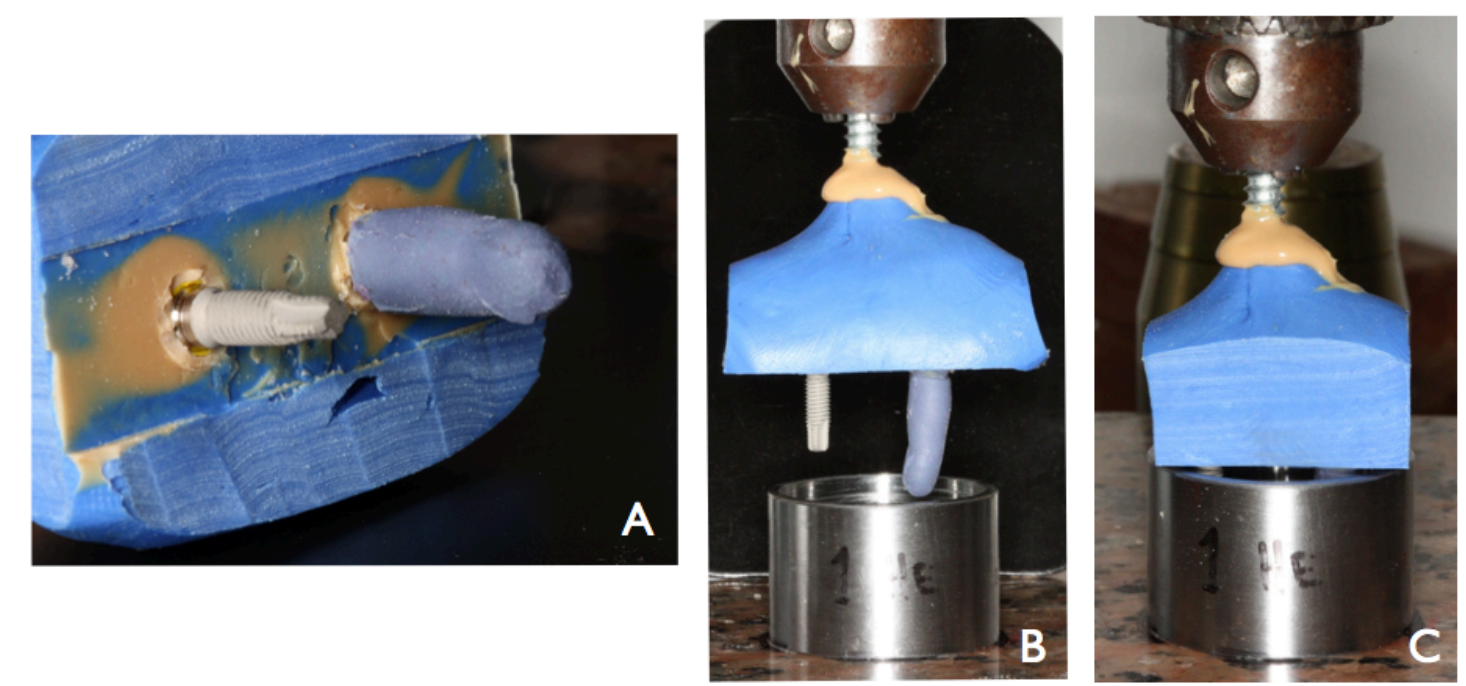

Figura 11. Confecção dos corpos de prova em poliuretano para ciclagem. A - Inserção do dente e do conjunto munhão-implante no molde de transferência; B e C - Deslocamento vertical do conjunto na matriz contendo o poliuretano.

Para a aplicação da carga durante o ensaio, foram utilizadas pontas que simulam a oclusão antagonista. Estas pontas foram obtidas através da escultura de um bloco em resina Duralay 66 (Reliance, EUA) que foi acomodado sobre a superfície de uma das PPF's, como uma restauração provisória pela técnica direta, favorecendo o engrenamento oclusal em máxima intercuspidação. Após a escultura, o elemento antagonista foi moldado e duplicado 7 vezes em resina Duralay (Reliance, EUA) para posterior fundição em Ni-Cr (Verabond II, Aalbadent, EUA) sem deixar resíduos. O protocolo de fundição seguiu os mesmos passos já 
descritos para confecção das estruturas metálicas das PPFs. Os antagonistas já fundidos foram jateados e receberam acabamento com fresas/pedras montadas e ajustes oclusais para serem usados na ciclagem sem que houvesse prematuridades ou interferências oclusais (figura 12).
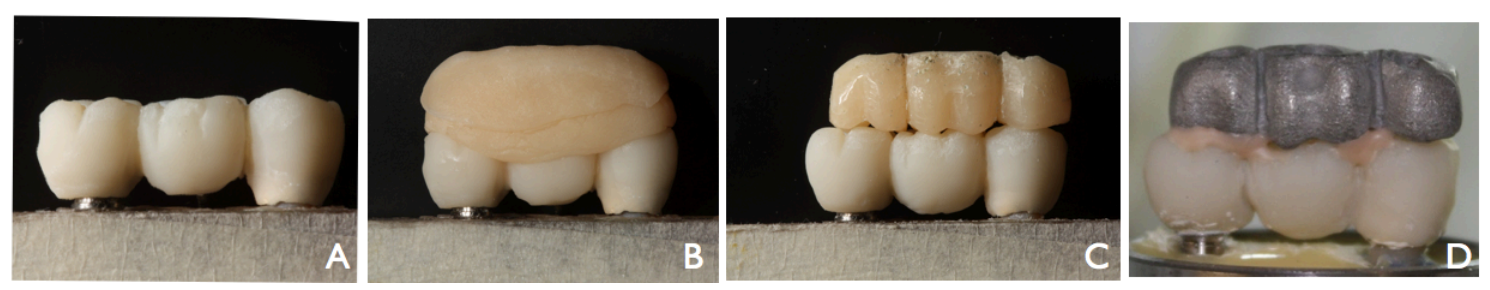

Figura 12. Confecção da PPF antagonista para ciclagem. A - PPF assentada sobre o modelo mestre; B - Porção de resina Duralay 66 acomodada sobre a PPF; C - Escultura da PPF antagonista pela técnica direta; D Replicação da escultura e fundição em Ni-Cr.

Na sequência as PPFs foram cimentadas sobre o seu respectivo conjunto implantemunhão utilizando-se cimento temporário (RelyX Temp NE, 3M ESPE, Seefeld, Alemanha). O cimento foi aplicado no interior das PPFs e estas foram assentadas sobre os corpos de prova em poliuretano. Para a cimentação foi utilizado um dispositivo metálico, acoplado a um delineador modificado na oficina de Precisão do Departamento de Materiais Dentários e Prótese (FORP-USP), de modo a padronizar o eixo de inserção das PPFs e a pressão de cimentação $(6 \mathrm{~kg})$. Os excessos de cimento foram removidos com instrumentos manuais e os corpos de prova foram armazenados em água a $37^{\circ} \mathrm{C}$ por 24 horas. Um cimento temporário foi utilizado pois haveria necessidade de remoção das próteses para análises posteriores (figura 13). 


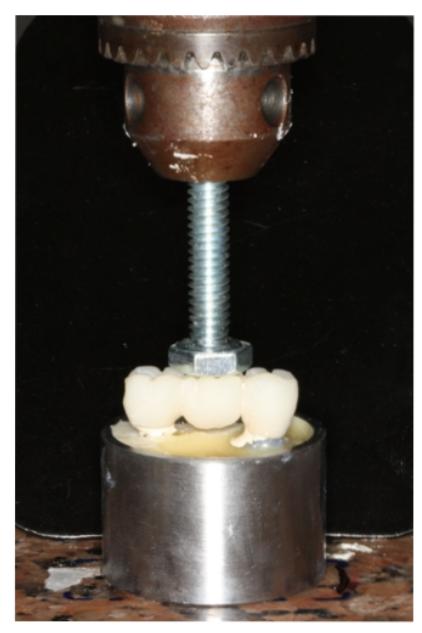

Figura 13. Cimentação provisória com pressão controlada por delineador modificado.

Os ensaios de aplicação de carga cíclica, simulando-se o efeito da mastigação humana, foram realizados em uma máquina de ciclagem mecânica (Erios ER 37000, São Paulo, SP, Brasil) do Laboratório Integrado de Pesquisa em Biocompatibilidade de Materiais - LIPEM FORP-USP. Esse equipamento permite a condução de ensaios dinâmicos de fadiga sobre 7 corpos de prova simultaneamente (um grupo). A força gerada sobre o corpo de prova em cada ciclo de carga é dada por um sistema pneumático. Os corpos de prova foram fixados com cola de cianoacrilato (SuperBonder, Henkel Loctite Adesivos LTDA, Itapevi, SP, Brasil) a uma base/porta-matriz em teflon e os conjuntos posicionados nos nichos da base da máquina de simulação de carga cíclica, fixados por meio de 3 parafusos para a prevenção de qualquer micromovimento de forma que a ponta aplicadora de carga, simulando dentes antagonistas, tocasse a superfície oclusal da prótese parcial fixa. Para a fixação dos elementos antagonistas na máquina, estes foram ocluídos sobre as PPFs e fixados com cera a estas. Na haste superior da máquina um parafuso foi inserido e unido ao elemento antagonista por meio de resina acrílica, de forma a produzir um conjunto resistente ao ensaio cíclico subsequente. Uma carga de $120 \mathrm{~N}$ foi aplicada por 1.000 .000 de ciclos na frequência de $2 \mathrm{~Hz}$, o que corresponde a aproximadamente dois anos de uso da prótese (Kim et al., 2009) (figura 14). 

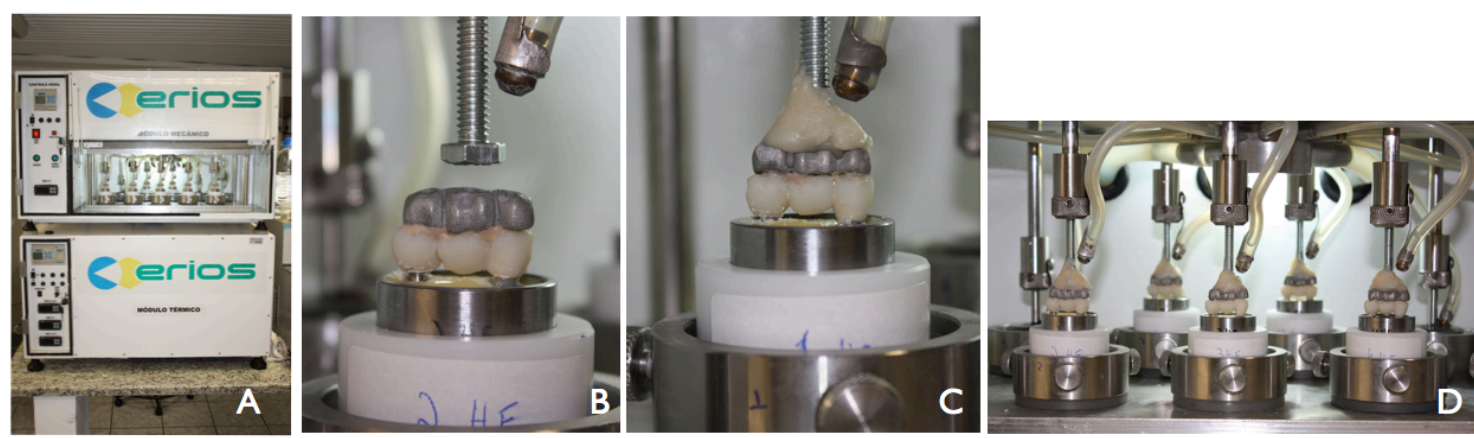

Figura 14. Ciclagem mecânica. A - Máquina de ciclagem utilizada para o ensaio; B - Fixação em cera do elemento antagonista sobre a PPF; C - Fixação do antagonista com resina acrílica na haste da máquina; D Corpos de prova preparados para ciclagem.

\subsection{Desajuste Vertical: Obtenção e análise dos dados}

Para as leituras utilizou-se um microscópio óptico comparador (Leica Microsystems, Wetzlar, Alemanha) com aumento de 40x. Cada PPF foi avaliada em 4 tempos de confecção da prótese: antes do procedimento de soldagem (retentores separados), após a soldagem, após a aplicação do revestimento cerâmico e após a ciclagem mecânica. A peça a ser analisada foi encaixada no modelo mestre e este levado ao microscópio para tomada das imagens. Foram realizadas 3 leituras em cada face: mesial, distal, vestibular e lingual, tanto da área de simulação do dente natural quanto da região do implante. Para cada retentor foi obtida uma média $(\mu \mathrm{m})+$ desvio padrão para cada um dos tempos analisados (figura 15). 

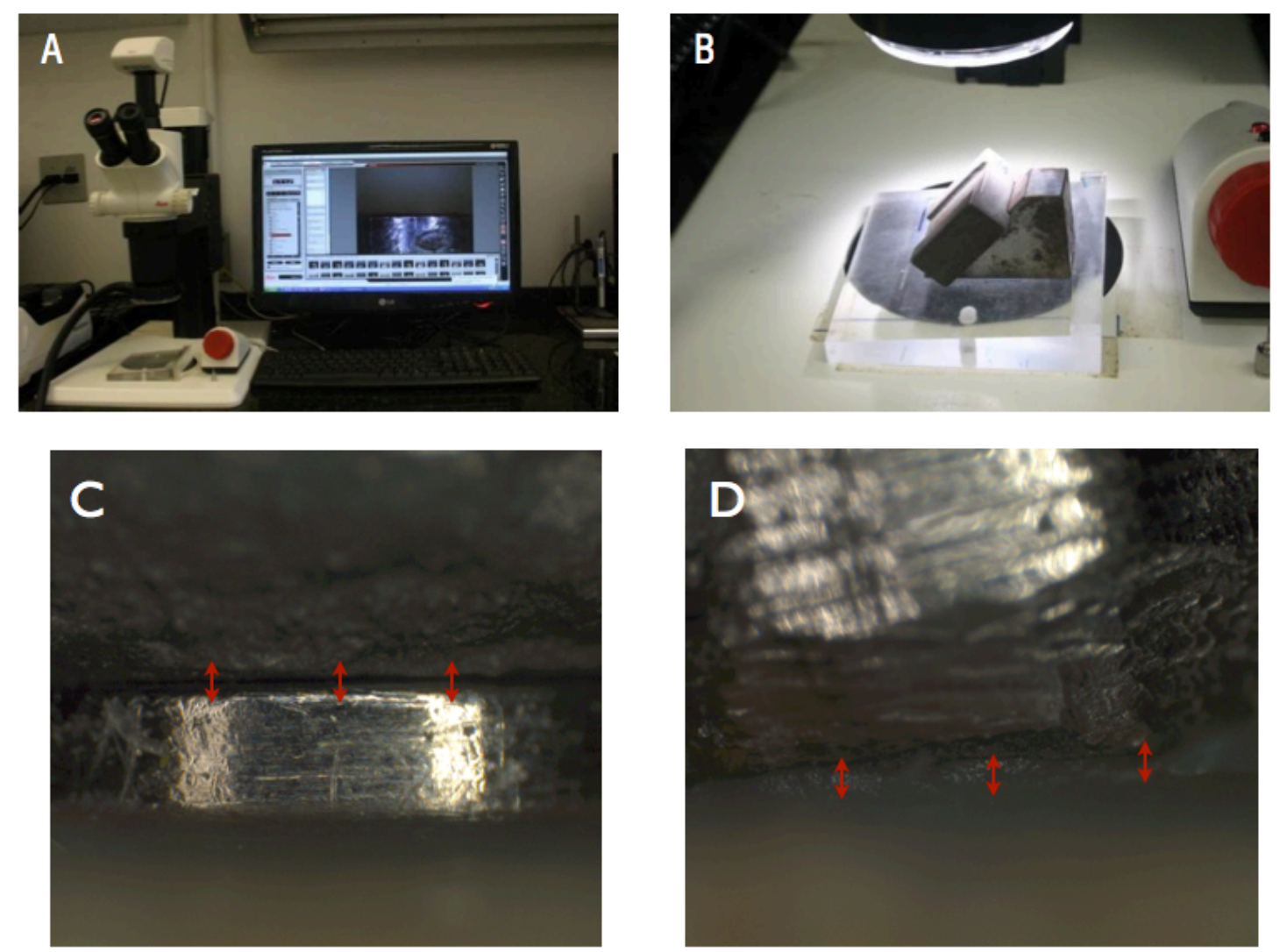

Figura 15. A - Microscópio óptico comparador utilizado para leituras. B - Bases anguladas para leituras das faces proximais, $\mathrm{C}$ e D -Imagens obtidas e referências de medições para implante e dente respectivamente.

Os dados obtidos dos níveis de assentamento das estruturas protéticas nos 4 tempos de confecção (antes solda, após solda, após cerâmica e após ciclagem) para os três tipos de conexão protética (HE, HI e CM) foram comparados e analisados estatisticamente. A análise estatística teve por objetivos comparar cada grupo (conexão protética) nos diferentes momentos (4 tempos) e as diferenças de desajuste entre o retentor implantossuportado e dentossuportado nos momentos apresentados em cada grupo. As comparações foram realizadas utilizando Modelo Linear de Efeitos Mistos (efeitos aleatórios e fixos). Este modelo é utilizado na análise de dados onde respostas de um mesmo corpo de prova estão agrupadas e a suposição de independência entre as observações num mesmo grupo não é adequada (Schall, 1991). Para a utilização deste modelo, é preciso que seus resíduos tenham distribuição normal com média zero e variância constante. Como tal pressuposto foi violado, 
realizou-se uma transformação logarítmica na variável resposta. O ajuste do modelo foi feito através do procedimento PROC MIXED e a análise estatística desenvolvida no software SAS/STAT® (versão 9,1 SAS Insitute Inc. Cary, NC, EUA).

\subsection{Percentual de Falhas na Prótese: Obtenção e análise dos dados}

Para a análise do percentual de falhas na prótese foram consideradas a ocorrência de trincas/fraturas do revestimento cerâmico ou decimentações da estrutura após o procedimento de ciclagem.

Após a finalização dos procedimentos de ciclagem mecânica, as peças cimentadas provisoriamente sobre os corpos de prova em poliuretano foram removidas delicadamente dos retentores por meio de um saca-próteses e inspecionadas quanto a presença de algum tipo de ocorrência como lascas, trincas ou fraturas. A contagem de ocorrências se deu por prótese, face e localização, ou seja, 7 próteses por grupo sendo 5 faces para os retentores (mesial, distal, vestibular, lingual e oclusal) e 6 faces no pôntico (todas as anteriores somadas à área gengival), totalizando 16 faces analisadas por corpo de prova. A ocorrência de decimentações foi avaliada por inspeção manual antes da utilização do saca-próteses. Os resultados foram expressos por percentual de ocorrência de falhas em relação ao número total de próteses para cada um dos três grupos e submetidos a análise descritiva da localização das falhas (figura 16). 

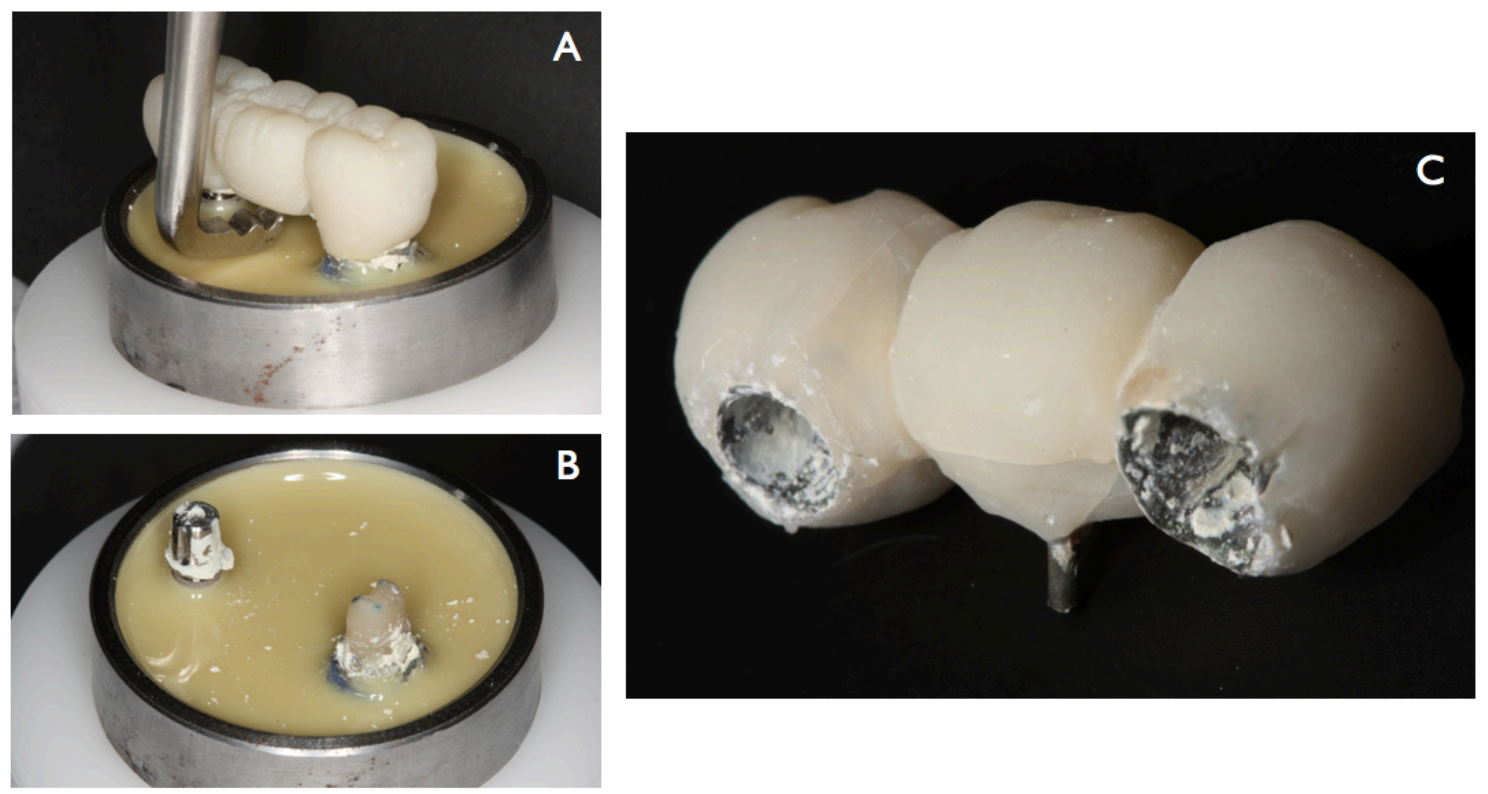

Figura 16. Procedimento de decimentação das PPFs para análise do percentual de falhas. A - Utilização delicada do saca-próteses; B - Corpo de prova após a estrutura removida; C - PPF removida para inspeção visual quanto a presença de trincas/fraturas cerâmicas.

\subsection{Ensaio Fotoelástico: Obtenção das imagens e análise qualitativa}

A verificação das tensões geradas no dente natural e implante foi realizada por meio de análise fotoelástica de transmissão. Para obtenção dos modelos fotoelásticos foram confeccionados três moldes de silicone (Silicone Master, Talladium INC, EUA) cujas câmaras de molde reproduziram a forma do dente e dos implantes do modelo mestre, nas diferentes situações propostas. As transferências de posição do modelo mestre foram realizadas com as próprias próteses fixas. A opção por esse tipo de transferência visou anular qualquer tipo de viés de confecção das peças com risco de gerar tensões secundárias no modelo fotoelástico caso tivesse sido realizada por meio de transferentes universais.Após a presa final do silicone o modelo mestre foi removido e foram encaixados no molde um conjunto munhão-implante (para cada grupo) e um dente preparado com ligamento periodontal em poliéter já descrito previamente. Os implantes foram incluídos na resina fotoelástica sem qualquer material interposto, o que simula a osseointegração. Obtido esse molde a resina fotoelástica do tipo Araldite GY279 e o endurecedor Aradur 2963 (Huntsman) foi cuidadosamente manipulada na 
proporção de $40 \mathrm{ml}$ para $19,20 \mathrm{ml}$, respectivamente. A mistura foi levada ao interior de uma câmara de vácuo durante 15 minutos para eliminação de bolhas resultantes da reação inicial entre os componentes da resina. A resina foi vertida na câmara do molde de silicone, incluindo o dente e o implante no material fotoelástico. Para a completa polimerização da resina o conjunto foi acondicionado em local fechado àtemperatura ambiente, por 72 horas. Foram obtidos 3 modelos fotoelásticos para as diferentes situações simuladas: 3 tipos de implantes (HE, HI, CM) com suas respectivas próteses parciais fixas rígidas (figura 17).

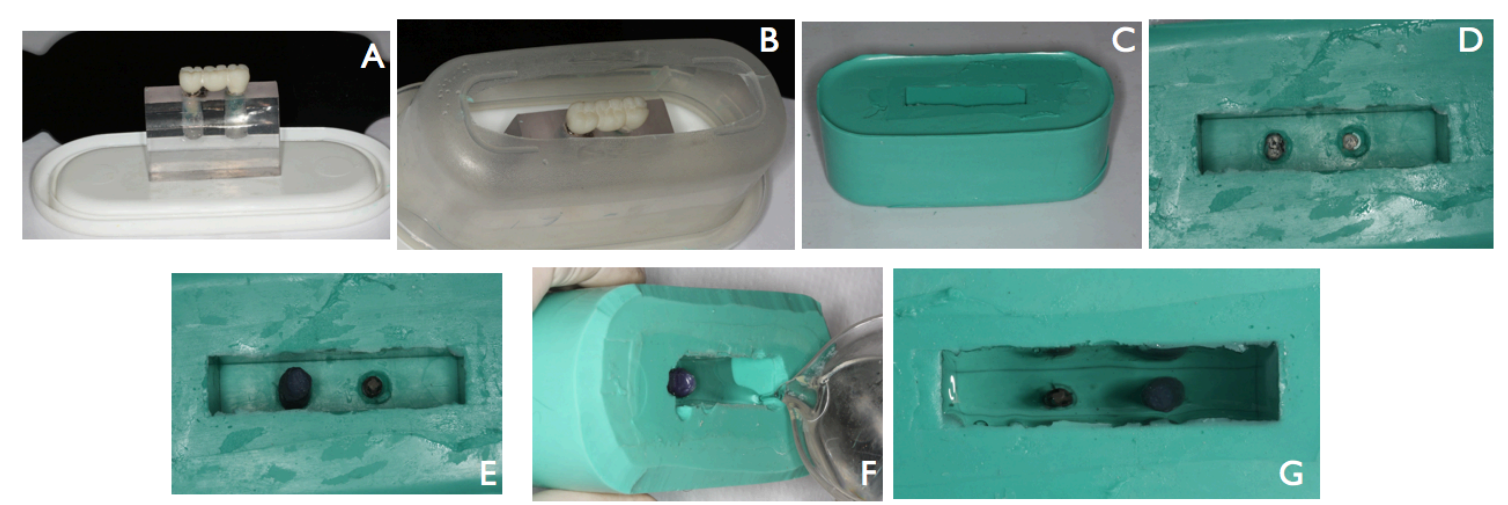

Figura 17. Confecção dos modelos fotoelásticos. A - Conjunto modelo mestre posicionado no dispositivo para inserção da silicona; B - Dispositivo preparado para recebimento da silicona; C e D - Molde de silicona finalizado; E - Inserção de um elemento dental com ligamento em poliéter + conjunto munhão-implante no molde; F - Manipulação e vazamento da resina fotoelástica; G - Modelo fotoelástico aguardando polimerização de 72 horas para o ensaio.

Os modelos fotoelásticos foram levados ao polariscópio (PS-100 Polarimeter Systems/Strainoptics, Inc., North Wales, EUA) para a realização das análises. Registros fotográficos de cada situação de interesse de análise foram realizados utilizando-se uma câmera digital (EOS Rebel XSi, Canon, Tóquio, Japão) acoplada ao polariscópio. Um dispositivo para aplicação de cargas composto por uma célula de carga de 50 kgf (Kratos, São Paulo, Brasil) e um leitor de carga (IKE-01, Kratos) e diferentes modelos de pontas aplicadoras de cargas foram acopladas ao polariscópio, ajustado no modo de polarização circular, para análise qualitativa. Os modelos de ponta de aplicação de carga utilizados foram: 1. puntiforme - ponta simples para carregamento no pré-molar com 5kgf; 2. puntiforme 
simultânea - ponta dupla para carregamento dos dois retentores (pré-molar e implante) ao mesmo tempo, com carga de $10 \mathrm{kgf}$; 3. oclusal distribuído - ponta simulando a oclusão antagonista do modelo com carga de 10kgf. Esses valores de carga foram determinados em estudos prévios (Menani et al., 2011), e visam não exceder o limite elástico do material fotoelástico e limitar a presença de franjas até a de $3^{\mathrm{a}}$. ordem. A ponta de carregamento oclusal utilizada foi a mesma do elemento metálico antagonista utilizado na ciclagem mecânica, cuja confecção foi descrita previamente. 
4. Resultados 


\subsection{Desajuste Vertical:}

Os valores médios de desajuste vertical $(\mu \mathrm{m})$ de cada grupo (HE, HI e CM), divididos por retentor analisado (dente ou implante) e tempo de confecção (antes da solda, depois da solda, depois da cerâmica e depois da ciclagem) assim como os Desvios Padrão obtidos, são apresentados na tabela 1 e gráficos de 1 a 3 .

Tabela 1. Médias $(\mu \mathrm{m})$ e desvio padrão do desajuste vertical para os grupos de conexões protéticas (Hex. Externo, Hex. Interno e Cone-Morse) em cada tipo de retentor (dente ou implante) para os quatro tempos analisados (antes solda, depois solda, depois cerâmica e depois ciclagem).

\begin{tabular}{cccccc} 
& & \multicolumn{2}{c}{ ANTES SOLDA } & \multicolumn{2}{c}{ DEPOIS SOLDA } \\
\cline { 2 - 5 } & & Dente & Implante & Dente & Implante \\
\hline \multirow{2}{*}{ Hex. Exterr } & Média $(\mu \mathrm{m})$ & $279,4 \vdots$ & 120,00 & 282,57 & 226,14 \\
& Desv. Pad & 99,71 & 146,85 & 62,57 & 139,68 \\
\hline \multirow{2}{*}{ Hex. Intern } & Média $(\mu \mathrm{m})$ & $330,4 \vdots$ & 104,71 & 337,29 & 150,71 \\
& Desv. Pad & 96,27 & 18,24 & 74,92 & 52,30 \\
\hline \multirow{2}{*}{ Cone-Mors } & Média $(\mu \mathrm{m})$ & $313,8 \epsilon$ & 78,43 & 237,29 & 139,14 \\
& Desv. Pad & 81,22 & 7,48 & 25,79 & 68,20 \\
\hline & & & & \\
& & DEPOIS CERÂMICA & DEPOIS CICLAGEM \\
\cline { 2 - 6 } & Dente & Implante & Dente & Implante \\
\hline \multirow{2}{*}{ Hex. Exterr } & Média $(\mu \mathrm{m})$ & $388,8($ & 316,14 & 552,29 & 256,00 \\
& Desv. Pad & 90,06 & 160,30 & 143,14 & 53,52 \\
\hline \multirow{2}{*}{ Hex. Intern } & Média $(\mu \mathrm{m})$ & $392,2 \complement$ & 237,14 & 466,71 & 278,29 \\
& Desv. Pad & $131,6:$ & 121,43 & 122,98 & 112,94 \\
\hline \multirow{2}{*}{ Cone-Mors } & Média $(\mu \mathrm{m})$ & $343,4 \vdots$ & 210,71 & 376,14 & 207,43 \\
& Desv. Pad & 51,91 & 100,30 & 68,04 & 86,07 \\
\hline
\end{tabular}




\section{Hexágono Externo}

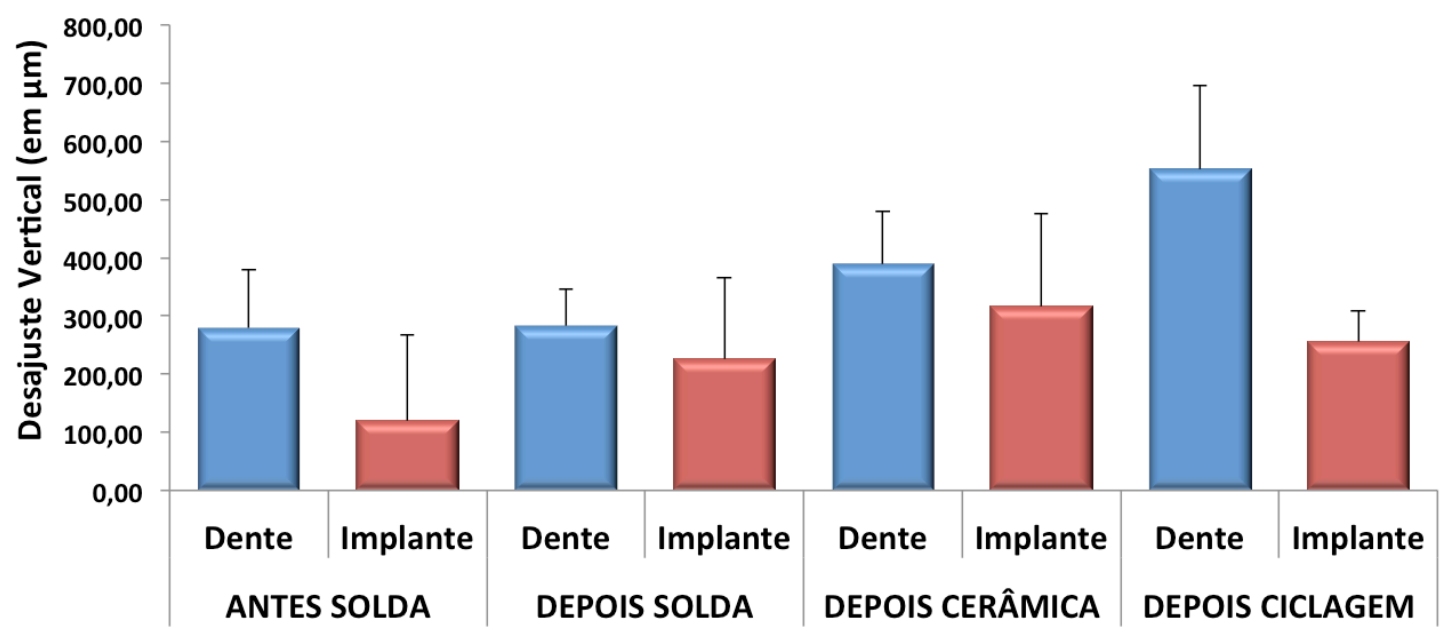

Gráfico 1. Desajustes verticais aferidos para o grupo Hexágono Externo em cada um dos tempos de confecção das PPF's para ambos os retentores. Valores expressos em médias $(\mu \mathrm{m})+$ desvio padrão.

\section{Hexágono Interno}

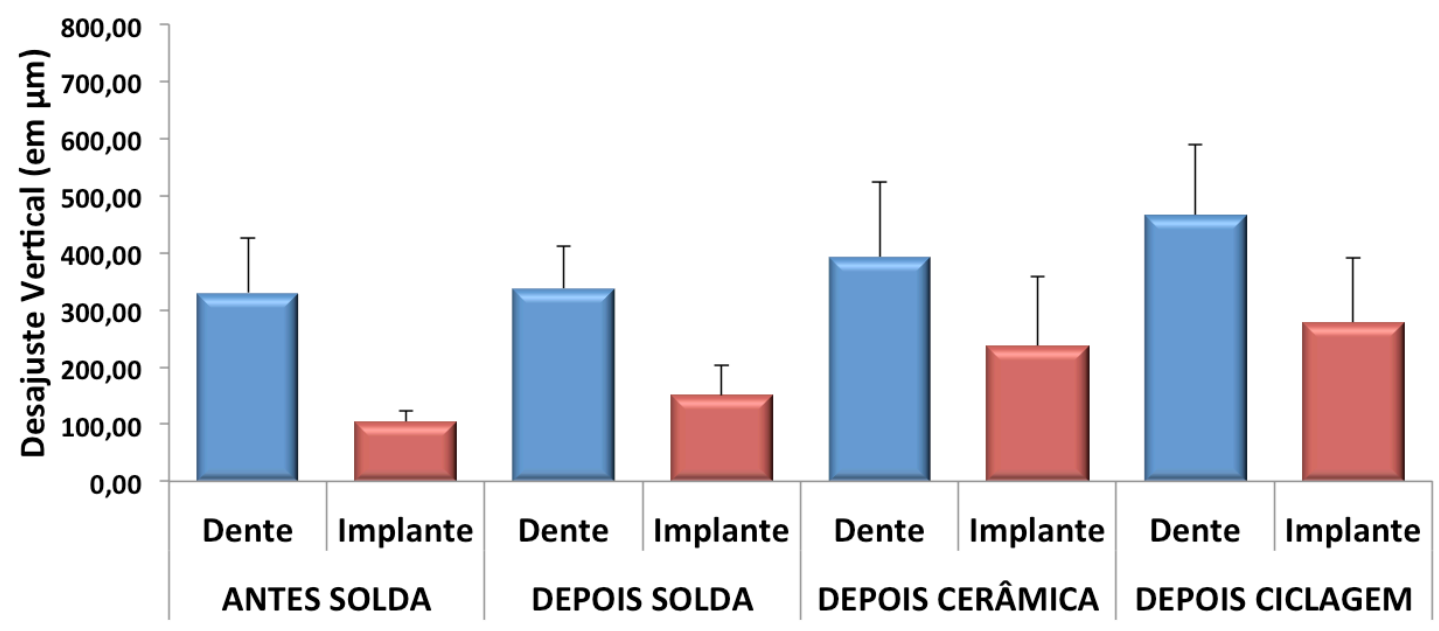

Gráfico 2. Desajustes verticais aferidos para o grupo Hexágono Interno em cada um dos tempos de confecção das PPF's para ambos os retentores. Valores expressos em médias $(\mu \mathrm{m})+$ desvio padrão. 


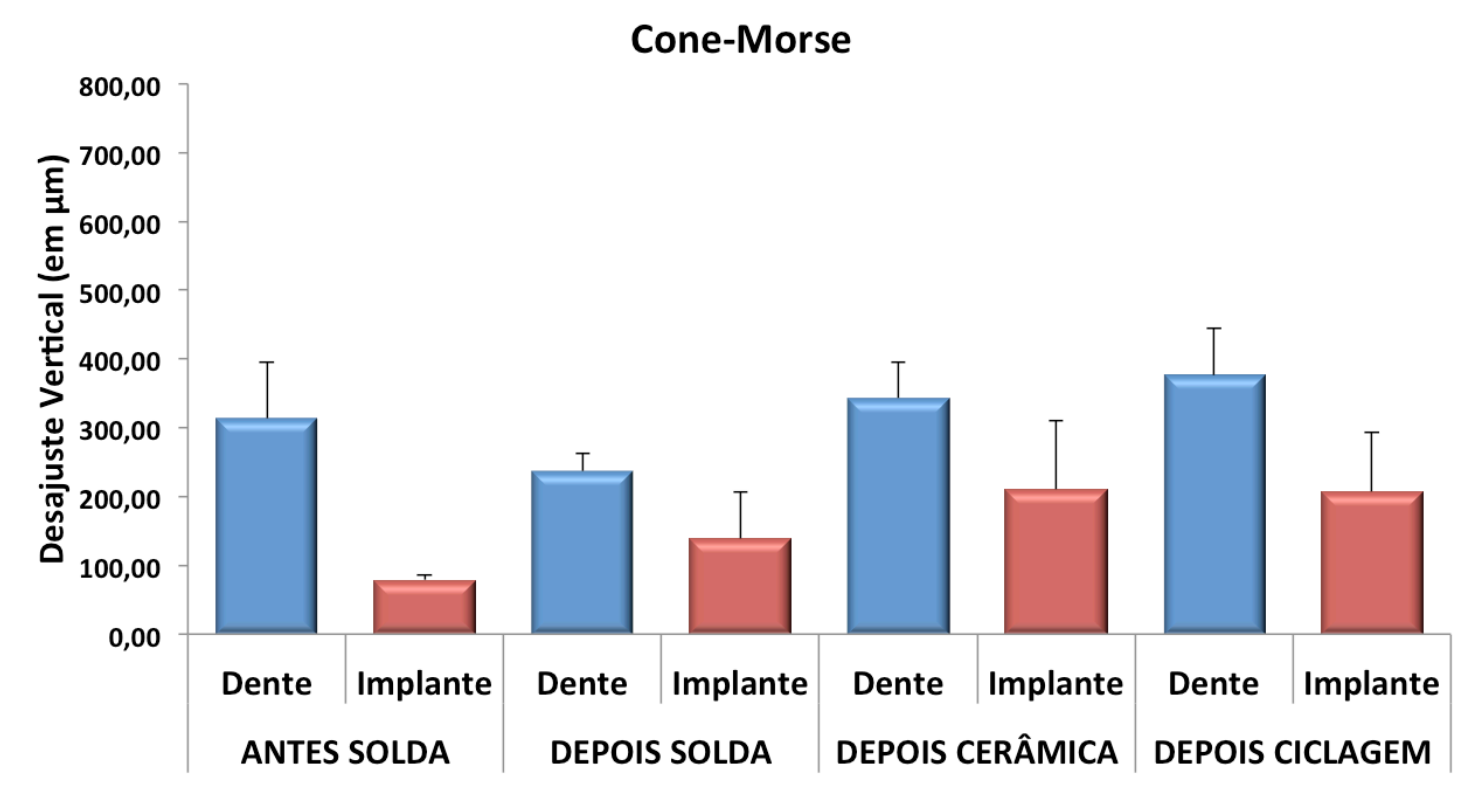

Gráfico 3. Desajustes verticais aferidos para o grupo Cone-Morse em cada um dos tempos de confecção das PPF's para ambos os retentores. Valores expressos em médias $(\mu \mathrm{m})+$ desvio padrão.

Na comparação do desajuste cervical entre as conexões protéticas por si só, não houve diferença estatisticamente significante entre os grupos estudados $(p=0,059)$. Entretanto, houve diferença significante nos níveis de desajuste entre os tempos de confecção da prótese para todos os grupos $(p<0,0001)$ e entre os elementos pilares, ou seja, entre dentes e implantes, sendo o desajuste na região dos dentes superior ao da região dos implantes em todos os tempos de confecção para todos os tipos de conexão protética.

Levando em consideração o desajuste na região do dente ao se comparar os tipos de conexão protética nos diferentes tempos de confecção, houve apenas diferença estatisticamente significante entre os implantes $\mathrm{HE}$ e $\mathrm{CM}$ (sendo $\mathrm{HE}>\mathrm{CM} p=0,008$ ) após o tempo 4 (depois ciclagem). Na região do implante, não houve diferenças significantes nestas mesmas circunstâncias.

Ao se comparar o desajuste entre dente e implante para cada tipo de conexão protética em cada tempo de confecção da prótese, nota-se diferença estatisticamente significante em todos os tempos para todas as conexões, excetuando os tempos 2 (depois solda) e 3 (depois cerâmica) para o sistema hexágono externo. 


\subsection{Percentual de falhas na prótese (análise descritiva):}

Ao se analisar as possíveis falhas nas próteses após ciclagem incluídas neste estudo (trincas/fraturas e/ou decimentações), encontrou-se para o grupo Hexágono Externo um percentual de falha após ciclagem de $28,57 \%$, tendo sido encontradas trincas/fraturas em 2 das 7 próteses, sendo 1 trinca na área do retentor dente e 1 em área de pôntico.

Para o grupo Hexágono Interno encontrou-se um percentual de falha após ciclagem também de $28,57 \%$ uma vez que 2 das 7 próteses apresentaram trincas. A distribuição destas, no entanto, foi maior com 2 trincas na área de pôntico e 1 na área do retentor implante.

Para o grupo Cone-Morse obteve-se o maior percentual de falha, no caso $71,42 \%$. Neste grupo 5 das 7 próteses apresentaram trincas e/ou fraturas, sendo 4 faces com fratura na área cervical do retentor dente, 3 trincas na área de pôntico e 3 trincas na área do retentor implante.

\subsection{Análise Fotoelástica (análise descritiva):}

Partindo dos modelos fotoelásticos neutros sem tensão residual (figura 18), tem-se a primeira carga aplicada, puntiforme na região do pré-molar (dente 45 ) com $5 \mathrm{kgf}$. Ao se analisar as imagens obtidas (figura 19), nota-se que para o grupo HE houve a formação de franjas de primeira ordem na região apical do dente e de segunda ordem em sua região cervical mesial. Na porção apical do implante nota-se o início da formação de uma primeira ordem de franja, porém tênue. Para o grupo HI, houve a formação de franjas de primeira ordem na região cervical mesial do elemento dental mas de segunda ordem na porção mais apical deste. Na região apical do implante nota-se também o início da formação de uma primeira ordem de franja também tênue. Para o grupo CM nota-se a formação de ordens de franja de primeira classe nas regiões cervical e apical do elemento dental, porém distribuídas 
de maneira mais uniforme ao longo da raiz. Na região do implante também nota-se a formação de uma primeira ordem de franja tênue, porém mais intensa que nos grupos anteriores.

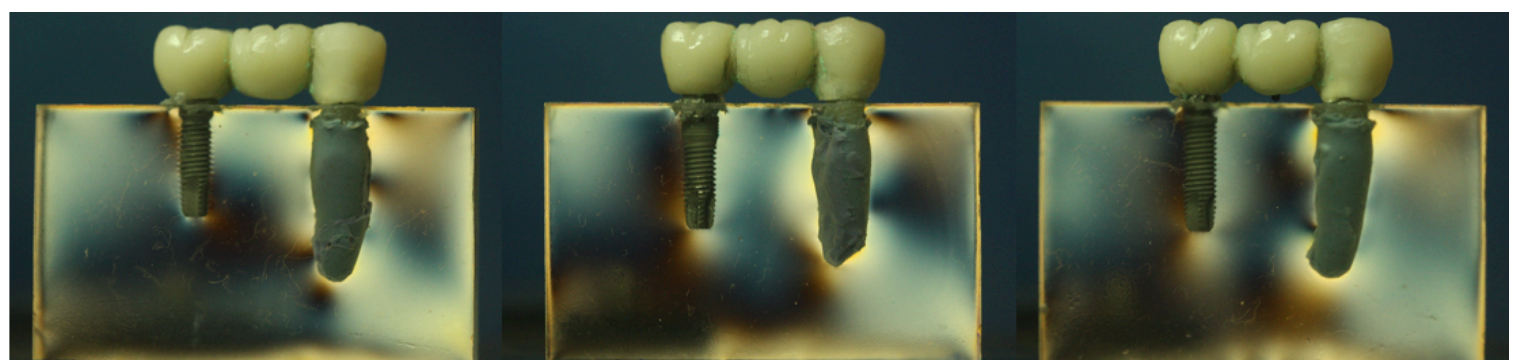

Figura 18. Modelos fotoelásticos neutros, sem tensão residual. Da esquerda para direita: HE, HI e CM.

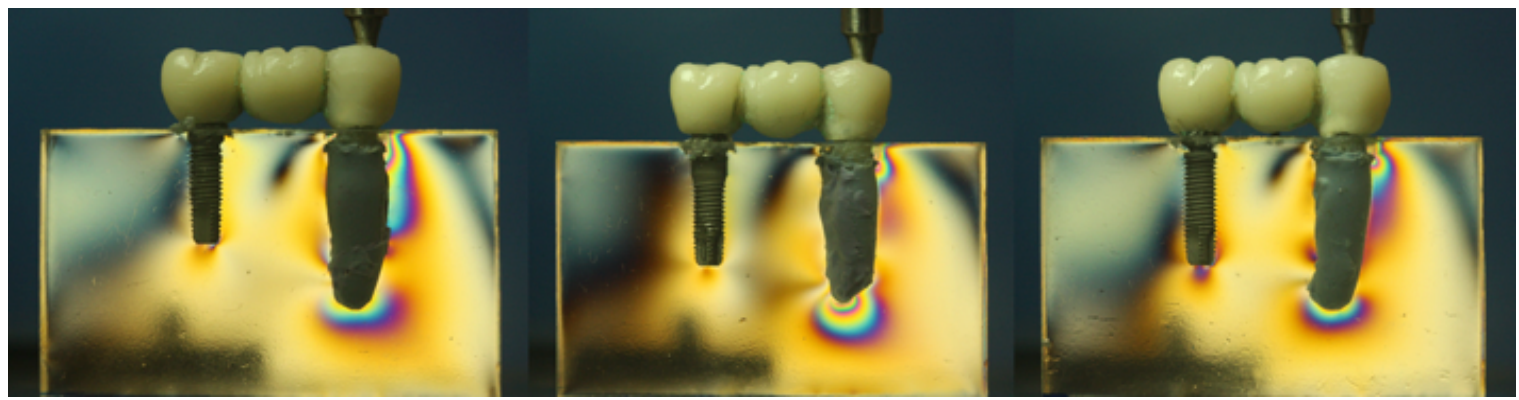

Figura 19. Carga puntiforme dente 45 com 5Kgf. Da esquerda para direita: HE, HI e CM.

Seguindo a análise para a carga puntiforme simultânea (pilar e dente ao mesmo tempo) com 10 kgf (figura 20), temos para o grupo HE a formação de franjas de segunda ordem na região cervical mesial do elemento dental, que recebeu também ao longo de sua raiz franjas de primeira ordem com maior intensidade na porção apical. Na área do implante temos franjas de segunda e terceira ordem na porção apical e primeira e segunda ordem nos terços médio e cervical. Na região cervical nota-se uma concentração de forças mais ampla no osso circundante. Para o grupo HI temos a formação de franjas de segunda ordem na região cervical mesial e apical do elemento dental (com o início da formação de franjas de terceira ordem nesta região). No implante temos a formação de franjas de segunda ordem na região apical e primeira ordem na região cervical, que mostrou-se mais preservada que no grupo HE. Para o grupo CM, temos a formação de franjas de primeira ordem bem distribuídas ao 
redor do elemento dental com maior concentração na região apical e na porção cervical mesial (onde nota-se o início da formação de uma franja de segunda ordem). No implante contudo nota-se a formação de franjas de terceira ordem na porção apical e primeira ordem na região cervical e terço médio, com preservação ainda maior na região cervical que nos grupos HE e HI.

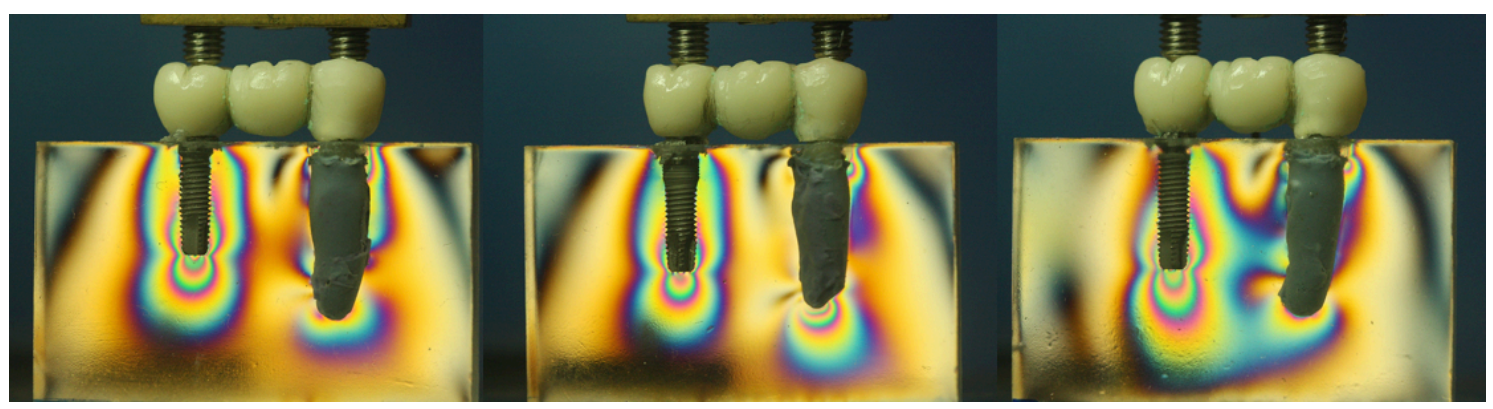

Figura 20. Carga puntiforme simultânea (dente e implante) com 10Kgf. Da esquerda para direita: HE, HI e CM.

Por fim, para a análise do carregamento oclusal distribuído com 10kgf (figura 21), temos para o grupo HE a formação de franjas de primeira ordem nas regiões apical e cervical do elemento dental e de primeira e segunda ordem na região do implante, sendo a maior concentração de tensão a região apical deste. Para o grupo HI, temos uma situação similar ao grupo HE, porém com maior grau de intensidade nas regiões apical do dente e cervical do implante. Uma pequena franja de primeira ordem foi notada na área cervical mesial do elemento dental, de menor magnitude que no grupo HE. Por fim, para o grupo CM nota-se franjas de segunda e terceira ordem na porção apical do implante e franjas de primeira e segunda ordem ao longo do corpo do implante. O elemento dental por sua vez apresentou pouca ou nenhuma deformação, com apenas indícios de formação de franjas na região distal apical e cervical. 


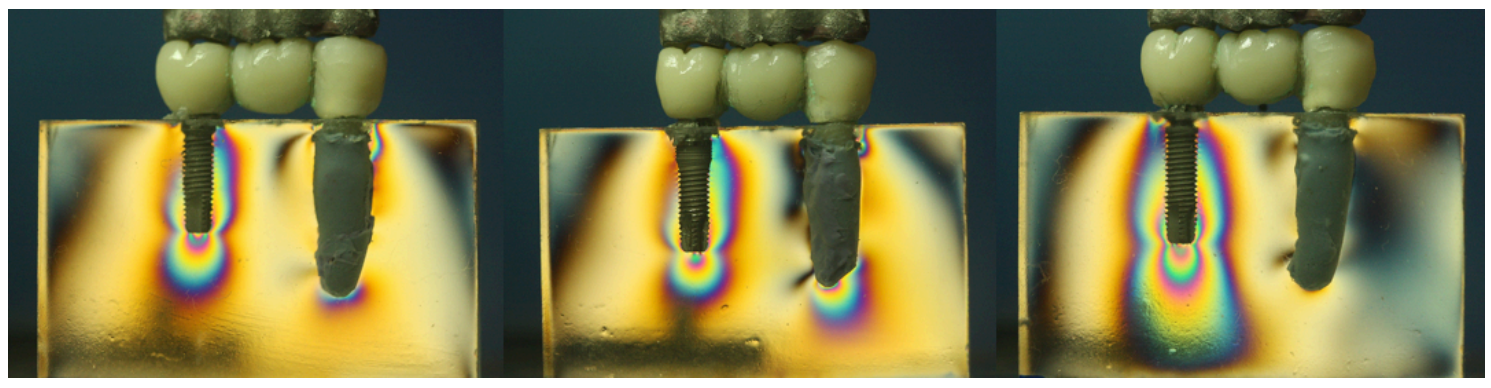

Figura 21. Carga oclusal distribuída com 10Kgf. Da esquerda para direita: HE, HI e CM. 


\section{DiscusรÃa}


Muitas vezes frente a uma área edêntula, inúmeros motivos podem dificultar uma reabilitação ideal trabalhando apenas com próteses implantossuportadas, sejam elas unidas ou unitárias (Lindh et al., 2008). Entretanto, dificuldades anatômicas como pouca altura/espessura óssea podem inviabilizar o tratamento convencional sendo necessária a união entre dente e implante para a execução de uma prótese parcial fixa (Chee et al., 2010; Hoffmann, Zafiropoulos, 2010; Mamalis et al., 2010).

Apesar de inúmeros trabalhos indicarem conexões semi-rígidas para a viabilização desta união devido a minimização de tensões ao redor do dente e da região periimplantar (Chee et al., 2010), sabe-se que, apesar de mecanicamente o sistema ser extremamente favorável, existe um risco potencial de intrusão do elemento dental (Block et al., 2002). A conexão rígida por sua vez têm se mostrado mais favorável para esse tipo de união, contudo apresenta o revés do maior tensão no tecido ósseo circundante tanto para dente quanto para implantes (Carrillo et al., 2010; Lindh et al., 2001).

Toda prótese parcial fixa metalocerâmica está suscetível a inúmeros processos inerentes à sua confecção (fundição, solda, aplicação do revestimento estético), etapas estas que influenciam em pequeno ou maior grau no desajuste vertical das peças.

No presente estudo notou-se um aumento significante nos níveis de desajuste para todos os tempos de confecção das próteses para todos os grupos, porém sem diferença significante entre eles. Notou-se um aumento do desajuste após a solda TIG para todos os grupos (excetuando o grupo CM). Tal fato pode ser explicado pelo espaço criado pela cortadora de precisão para posterior solda que, por ser bastante estreito, justificou a não interposição de nenhum material para preenchimento na soldagem. Mesmo sendo muito pouco intensa, a solda TIG pode gerar uma pequena contração na união principalmente quando há uma certa distância entre ambos os fragmentos sem interposição de nenhum material de preenchimento (Barbi et al., 2012). Sendo assim, pode-se inferir que a contração 
da solda tenha sido o fator preponderante para o aumento do desajuste observado neste tempo de confecção.

A literatura relata inúmeros trabalhos que relacionam as queimas da cerâmica a desajustes verticais na região cervical de elementos pilares de coroas e próteses metalocerâmicas. A primeira razão que justifica esse comportamento se dá pela contração da porcelana após cocção (Shillingburg et al., 1973). O coping possui em sua região cervical uma espessura bastante delgada de metal, susceptível a distorções provenientes da força de contração da cerâmica. O fato de, para todos os grupos, encontrarmos valores de desajuste maiores para os copings sobre a área de dente do que para as áreas de implante corrobora ainda mais para tal afirmação, uma vez que o término em chanfro utilizado no dente fornece uma espessura de metal bastante delgada em comparação ao término mais espesso em metal na região do pilar implantossuportado. Faucher et al. (1980) em um estudo comparativo de desajuste cervical obtido através de diferentes tipos de término cervical em coroas metalocerâmicas, encontraram um maior desajuste cervical em términos do tipo chanfro em comparação aos términos em ombro e ombro biselado. Suas justificativas baseiam-se justamente na espessura de metal encontradas neste tipo de término, que pode sofrer distorção pela contração da cerâmica e é intensificado pelo maior número de elementos retentores em situações de próteses parciais fixas. Estas considerações aliadas as dificuldades metodológicas para confecção dos corpos de prova podem auxiliar no entendimento dos níveis de desajuste encontrados neste trabalho.

O aumento nos níveis de desajuste após a ciclagem pode ser explicado por possíveis deformações na peça após o ensaio de fadiga. Nota-se que ao se comparar os níveis de desajuste apenas entre os tempos 3 e 4 (após cerâmica e após ciclagem) o aumento nos níveis de desajuste segue uma tendência muito mais expressiva para o dente do que para o implante. Tal fato também pode ser explicado pela menor espessura de metal do coping nesta área, 
tornando-o mais susceptível a deformações após o período simulado de 2 anos de utilização da prótese.

A utilização de uma PPF de conexão rígida também implicou em falhas no revestimento estético representadas por trincas e fraturas em algumas faces das peças protéticas. Ao analisarmos os resultados, notou-se que quanto mais rígida fosse a conexão protética utilizada $(\mathrm{CM}>\mathrm{HI}>\mathrm{HE})$, maiores foram os índices de trincas e fraturas. Sabe-se que diferença de mobilidade entre dente natural e implante está na proporção de 5:1, o que provoca torque significante no implante (Weinberg; Kruger, 1994) e um comprometimento mecânico de todo o sistema, uma vez que o elemento dental funciona como um "cantilever contido". A conexão protética utilizada exerce influência e, segundo alguns trabalhos, deveria permitir algum grau de flexibilidade dentro da união parafusada, com exemplos de sistemas de hexágono externo possuindo junções com movimentos comparáveis ao dente natural (Gunne et al., 1997; Lundgreen; Laurell 2000). O tipo de conexão com hexágono interno aumenta a estabilidade da prótese, mas ao mesmo tempo pode aumentar a concentração de tensão em todo o sistema, tendo inclusive a defesa por parte de autores que indicam a utilização de implantes de hexágono externo como sendo mais favorável para esse tipo de união (Silva et al., 2010). Considerando que não houve nenhuma ocorrência de decimentação das próteses, a maior presença de trincas cerâmicas no grupo CM pode ser justificada por sua extrema rigidez associada ao sistema de "cantilever contido" promovido pelo elemento dental durante sua intrusão nos esforços mastigatórios, seguido pelo grupo HI (rigidez intermediária) e HE (rigidez inferior).

Transpondo essas considerações mecânicas para a análise fotoelástica, pode-se notar padrões de tensão bastante peculiares. Ao carregamento pontual no elemento dental, temos um resultado favorável na seguinte ordem: $\mathrm{CM}>\mathrm{HI}>\mathrm{HE}$. Nota-se que pela maior rigidez do sistema, no grupo CM boa parte da tensão da carga dissipa-se na própria prótese preservando 
o elemento dental uma vez que o padrão de franjas observado é inferior aos outros grupos. Tal acúmulo de energia nas peças pode justificar tanto a deformação da estrutura (consequentemente o desajuste cervical aumentado) quanto as trincas/fraturas do revestimento cerâmico encontradas. O grupo HI mostra um padrão semelhante porém com ordens de franja mais intensas e o HE, por sua vez, dissipa maior quantidade de tensão no osso periodontal com tensão razoavelmente superior na área cervical. Desta forma pode-se inferir que apesar do grupo HE limitar as falhas protéticas (trincas/fraturas) pela maior maleabilidade do sistema, as consequências são sentidas em maior grau pelas estruturas periodontais/periimplantares.

Ao se analisar os padrões encontrados para as cargas puntiformes simultâneas (dente e implante) e oclusal distribuída, percebe-se ainda mais nitidamente esse comportamento biomecânico. O grupo HE apresenta uma distribuição de tensões mais uniforme em toda a superfície do elemento dental e do implante, porém com áreas de franjas de segunda e terceira ordem e de intensidade relativamente alta nas regiões cervicais tanto do dente quanto do implante. Inúmeros trabalhos relatam a associação de tensões cervicais e perda óssea ao redor de dentes e implantes devido ao fato do osso cortical (mais denso) ser menos susceptível às tensões que o osso medular, resultando em reabsorção a longo prazo (Hanaoka et al., 2013; Pratheep et al., 2013). Dessa forma, o grupo HE mostrou ser mais agressivo ao osso cortical na região cervical que os demais, o que pode comprometer o sistema ao longo dos anos. $\mathrm{O}$ grupo HI apresentou um padrão de distribuição de tensões semelhante ao grupo HE, porém ao se analisar a região cervical tanto do elemento dental quanto do implante, nota-se uma redução dos níveis cervicais de tensão em relação ao primeiro grupo. Tal padrão pode ser explicado pela rigidez superior da conexão devido a presença de um hexágono mais volumoso, gerando menor deflexão e consequentemente transmitindo menor quantidade de tensão na área. Para o grupo $\mathrm{CM}$, tem-se um padrão de formação de tensão bastante 
interessante, principalmente ao ser analisar as regiões cervicais para dente e implante. Para ambas as situações de carregamento, nota-se que as tensões se distribuem com intensidades moderadas ao longo de toda a superfície do implante, mas há uma região óssea cervical preservada e praticamente livre de tensões exacerbadas. O protocolo de instalação sugerido pelo fabricante preconiza o posicionamento deste infra-ósseo pelo menos 1-2 mm, logo o implante estaria em uma posição subcrestal situado em uma região de osso medular, muito mais adaptada a receber tensões, preservando a região cervical (osso cortical), mais frágil e susceptível à reabsorção (Hanaoka et al., 2013; Pratheep et al., 2013). Logo, nota-se que a opção por esse tipo de protocolo de trabalho pode favorecer a manutenção do nível ósseo circundante a longo prazo mesmo para a associação dente-implante em uma PPF rígida. Ademais, ao analisarmos o padrão de franjas encontrado no elemento dental, nota-se padrões de menor intensidade na região cervical em relação aos demais grupos, sendo inclusive quase não perceptível ao carregamento oclusal. Tal conduta pode indicar uma maior tendência à preservação de concentração de tensões no dente pilar, favorecendo sua saúde periodontal a longo prazo devido a rigidez da conexão protética utilizada.

Embora os resultados obtidos pareçam promissores para o uso da conexão morse para a união dente-implante, mais estudos acerca desta se fazem necessários, principalmente associando a conexão morse à próteses parciais fíxas semi-rígidas e análise por elementos finitos das situações apresentadas, além de estudos in vivo controlados. 
6. CancLuSŨEs 
Dentro das limitações do estudo pode-se tecer as seguintes conclusões acerca da união dente-implante de forma rígida:

1) Os níveis de desajuste cervical tendem a aumentar durante as etapas de confecção da prótese para todas as conexões protéticas;

2) A fadiga mecânica tende a interferir no grau de desajuste vertical da prótese a longo prazo pela maior tendência à deformação das estruturas devido à pequena espessura metálica em algumas áreas (principalmente próximas ao dente); deve-se preconizar o uso de estruturas metálicas mais robustas para minimização destas ocorrências;

3) O aumento no percentual de falhas da prótese (trincas/fraturas) tende a ser proporcional ao aumento da rigidez da conexão protética (devido ao efeito de “cantilever contido" pela intrusão do elemento dental em comparação ao implante), sendo $\mathrm{CM}>\mathrm{HI}>\mathrm{HE}$;

4) A utilização de conexões protéticas menos rígidas tende a preservar as próteses (menor incidência de trincas/fraturas), mas também tende a aumentar as tensões nos elementos pilares e a tensão no osso circundante, em especial nas áreas cervicais (mais críticas - osso cortical);

5) A utilização de um sistema de conexão morse para a união dente-implante rígida tende a apresentar menor concentração de tensões nas regiões cervicais de dentes e implantes, preservando-os a longo prazo de maneira mais efetiva que as demais conexões protéticas devido ao menor grau de reabsorção. Entretanto, para tal deve-se preconizar a utilização de uma estrutura metálica mais reforçada para que haja a minimização da deformação da estrutura a longo prazo colaborando para a redução das trincas/fraturas (ainda que estas tenham maior risco de acontecer neste grupo). Apesar do maior risco de falhas na prótese (que pode ser refeita), há uma maior tendência à preservação dos elementos pilares. 


\section{REFERÊNCIAS BIBLIDGRÁfICAS}


Barbi FC, Camarini ET, Silva RS, Endo EH, Pereira JR. Comparative analysis of different joining techniques to improve the passive fit of cobalt-chromium superstructures.J ProsthetDent 2012;108:377-85.

Block MS, Lirette D, Gardiner D. Prospective evaluation of implants connected to teeth. Int J Oral Maxillofac Implants 2002;14:473-487.

Bragger U, Aeschlimann S, Burgin W, Hammerle CH, Lang NP. Biological and technical complications and failures with fixed partial dentures (FPD) on implants and teeth after four to five years of function. Clin Oral Impl Res 2001;12:26-34.

Carrillo $\mathrm{CH}$, Aliaga MH, Guirado JLC. Tooth-implant connection: A bibliographic review. Med Oral Patol Oral Cir Bucal 2010;1:387-394.

Cehreli M, Duyck J, Cooman M, Puers R, Naert I. Implant design and interface force transfer. Clin Oral Impl Res 2004;15:249-257.

Chee WW; Mordohai N. Tooth-to-implant connection: a systematic review of the literature and a case report utilizing a new connection design. Clin Impl Dent Rel Res 2010;12:122-133.

Eisenman E. Implant retained suprastrucuturespassivated to a stress free fit through spark erosion. QuintessenzZahntecnikImplantologie 1997, 12:1440. 
Faucher B, Nicholls J. Distortion related to margin design on porcelain-fused-to-metal restorations. J Prosthet Dent 1980;43:149-155.

Gunne J, Rangert B, Glantz PO. Functional loads on freestanding and connected implants in three-unit mandibular prostheses opposing complete dentures: an in vivo study. Int $\mathbf{J}$ Oral Maxillofac Implants 1999;23:335-341.

Hanaoka M, Gehrke SA, Mardegan F, Gennari CR, Taschieri S, Del Fabbro M, Corbella S. Influence of Implant/Abutment Connection on Stress Distribution to ImplantSurrounding Bone: A Finite Element Analysis. J Prosthodont 2014; doi: 10.1111/jopr.12150.

Hoffmann O, Zafiropoulos GG. The tooth implant connection: a review. J Oral Implantol 2010;23(2):194-200.

Hohmann A, Wolfram G, Gerger M, et al. Periodontal ligament hydrostatic pressure with areas of root resorption after application of a continuous torque movement. Angle Orthod 2007;77:653-659.

Kim S, Park J, Jeong J, Bae C, Bae T, Chee W. In vitro evaluation of reverse torque value of abutment screw and marginal opening in a screw- and cement- retained implant fixed partial denture design. Int J Oral Maxillofac Implants 2009; 24:1061-7

Lang NP, Pjetursson BE, Tan K, Bragger U, Egger M, Zwahlen M. A systematicreview of the survival and complication rates of fixed partial dentures (FPDs) after an observation 
period of at least 5 years. II. Combinedtooth--implant-supported FPDs. Clin Oral Implants Res 2004;15:643-53.

Lin $\mathrm{CH}$, Wang JC, Chang SH, et al. Evaluation of stress induced by implant type, number of splinted teeth, and variaions in periodontal support fixed partial dentures: a non-linear finite element analysis. J Periodontol 2010; 81:121-130.

Lin CL, Wang JC, Kuo YC. Numerical simulation on the biomechanical interactions of tooth/implant-supported system under various acclusal forces with rigid/non-rigid connections. J Biomech 2006;39:453-463.

Lindh T. Shoul we extract teeth to avoid tooth-implant combinations? J Oral Rehabil 2008;35(Suppl. 1):44-54.

Lindh T, Dahlgren S, Gunnarsson K, et al. Tooth-implant supported prostheses: a retrospective multicenter study. Int J Prosthodont 2001;14:321-328.

Lundgren D, Laurell L. Biomechanical aspects of fixed bridgework supported by natural teeth and endosseous implants. Periodontol 2000;4:23-40.

Mamalis A, Markopoulou K, Kaloumenos C, Analitis A. Splinting osseointegrated implants and natural teeth in partially edentulous patients: a systematic review of the literature and a case report. J Oral Implantol 2010;12:(epub ahead of print). 
Menani LR, Tiossi R, Torres EM, Ribeiro RF, Almeida Antunes RP. Photoelastic stress analysis of different designsof cement-retained fixed partial dentures on morse taper oral implants. J Craniofac Surg 2011;22:674-678.

Menicucci G, Mossolov A, Mozzati M, et al. Tooth-implant connection: some biomechanical aspects based on finite element analysis. Clin Oral Implants Res 2001:13:334-341.

Montarou CC, Gaylord TK. Two-wave-plate compensator method for single-point retardation measurements. Applied Optics 2004;43:6580-6595.

Naert IE, Duyck JA, Hosny MM, et al. Freestanding and tooth-implant connected prostheses in the treatment of partially edentulous patients Part II: an un to 15-years radiographic evaluation. Clin Oral Implants Res 2001;12:245-251.

Nagib NN. New formulas for phase retardance measurements of birefringent plates. Optics \& Laser Technol 1999;31:309-313.

Natali AN, Pavan PG, Ruggero AL. Evaluation of stress induced in peri-implant bone tissue by misfit in multi-implant prosthesis. Dent Mater 2006;22:388-395.

Nickenig HJ, Schafer C, Spiekermann H. Survival and complication rates ofcombined tooth-implant-supported fixed partial dentures. Clin Oral Implants Res. 2006;17:506-11. 
Nishimura RD, Ochiai KT, Caputto AA et al. Photoelastic stress analysis of load transfer to implants and natural teeth comparing rigid and semirigid connectors. J Prosthet Dent 1999;81:696-703.

Ozçelik T, Ersoy AE. An investigation of tooth/implant-supported fixedprosthesis designs with two different stress analysis methods: an in vitro study.J Prosthodont. 2007 MarApr;16(2):107-16.

Pratheep KV, Abraham A, Annapoorni $\quad$ H, Vigneshwaran S.Comparative evaluation of stresses in tooth implant connected fixed partial denture by $\mathrm{v}$ arying the implant designand position: $\quad$ a 3D finite element study.Indian $\quad J \quad$ Dent Res 2013;24:439-45.

Shillingburg HT Jr, Hobo S, Fisher DW, Preparation design and margin distortion in porcelain-fused-to-metal restorations. 1973.J ProsthetDent 2003;89:527-32.

Silva EF, Pellizzer EP, Mazaro JVQ, et al. Influence of the connector and implant design on the implant-tooth connected prostheses. Clin Impl Dent Rel Res 2010;12:254-262.

Velásquez-Plata D, Lutonsky J, Oshida Y, et al. A close-up look at na implant fracture: a case report. Int J Prosthodont 2002;22:483-491.

Weinberg LA, Kruger B. Biomechanical considerations when combining tooth-supported end implant-supported prostheses. Oral Surg Oral Med Pathol 1994;78:22-27. 